\title{
Medium chain length polyhydroxyalkanoates consisting primarily of unsaturated 3-hydroxy-5-cis-dodecanoate synthesized by newly isolated bacteria using crude glycerol
}

Amtiga Muangwong ${ }^{1}$, Thanawat Boontip ${ }^{1}$, Jittakan Pachimsawat ${ }^{2}$ and Suchada Chanprateep Napathorn ${ }^{1,2^{*}}$ (1)

\begin{abstract}
Background: Our study aimed to search for novel bacteria capable of producing polyhydroxyalkanoates (PHAs) using crude glycerol residue obtained from biodiesel production in which used cooking oils were the substrates.

Results: Newly isolated bacteria from soils in Thailand were screened for the efficient production of PHAs from crude glycerol. The bacterial strains were cultivated on glucose, refined glycerol, crude glycerol, or various cooking oils (canola oil, palm oil, soybean oil, sunflower oil, corn oil, grape seed oil, olive oil, rice bran oil, camellia seed oil) for growth and PHA production. The effects of the total organic carbon (TOC) concentration and the mole ratio of carbon to nitrogen were investigated in batch cultivation. ${ }^{1} \mathrm{H}$ NMR, two dimensional- ${ }^{1} \mathrm{H}$-correlation spectroscopy $\left(2 \mathrm{D}-{ }^{1} \mathrm{H}-\right.$ COSY) and ${ }^{13} \mathrm{C}$ NMR analyses confirmed four bacterial strains were capable of producing medium-chain-length PHAs (mcl-PHAs), consisting of 3-hydroxyoctanoate (3HO) and 3-hydroxy-5-cis-dodecanoate (3H5DD), from crude glycerol. On the basis of phenotypic features and genotypic investigations, the bacterial strains were assigned as: ASC1, Acinetobacter genus (94.9\% similarity); ASC2, Pseudomonas genus ( $99.2 \%$ similarity); ASC3, Enterobacter genus (99.2\% similarity); ASC4, Bacillus genus (98.4\% similarity). The highest amount of mcl-PHAs, $17.5 \pm 0.8 \mathrm{~g} / \mathrm{L}$ (content $61.8 \pm 3.3 \% \mathrm{wt})$, with $3 \mathrm{HO}(14.7 \pm 2.2 \mathrm{~mol} \%), 3 \mathrm{H} 5 \mathrm{DD}(85.3 \pm 2.2 \mathrm{~mol} \%)$, and a total biomass of $32.3 \pm 0.3 \mathrm{~g} / \mathrm{L}$, was obtained from Pseudomonas sp. ASC2 in batch cultivation after $36 \mathrm{~h}$. The mcl-PHAs recovered had a number-average molecular weight $\left(M_{N}\right)$ of $3.6 \times 10^{4} \mathrm{Da}$. Homopolymeric $3 \mathrm{H} 5 \mathrm{DD}$ was obtained when the cultivation time was prolonged to $96 \mathrm{~h}$.
\end{abstract}

Conclusions: Novel PHA-producing strains were isolated and identified. These bacterial strains are able to produce mcl-PHAs from crude glycerol. The mcl-PHAs produced contained a high percentage of 3H5DD, which suggests their future application as softeners mixed with other biomaterials. The unsaturated side chain of 3H5DD monomers containing double bounds offers additional potential for improving the properties of the mcl-PHAs or extending their applications to the food industry.

Keywords: Medium chain length PHAs, Crude glycerol, Used cooking oil, Acinetobacter sp., Pseudomonas sp., Enterobacter sp., Bacillus sp., 3-Hydroxyoctanoate, 3-Hydroxy-5-cis-dodecanoate (3H5DD)

\footnotetext{
*Correspondence: suchada.cha@chula.ac.th

${ }^{1}$ Department of Microbiology, Faculty of Science, Chulalongkorn

University, Phayathai Road, Patumwan, Bangkok 10330, Thailand

Full list of author information is available at the end of the article
} 


\section{Background}

Policy changes in various countries to enforce the use of biomass-derived fuels and bio-based polymers are current trends worldwide due to the depletion of fossil resources within the coming decades as well as global warming issues [1]. The sustainability of these bio-based industries has become an important concern that calls for a business strategy that integrates social, safety, health and environmental benefits with the technological and economic objectives of their activities [2]. The current trend to change the feedstock used from hydrocarbons to biological compounds has radically altered the technological basis of the biotechnology industry. Primarily, there is a need for technologies that enable the economical processing of complex biomass; for example, the production of biodiesel from renewable resources and the incorporation of the production of biodegradable polymers from organic wastes obtained from biodiesel processes remains a major challenge requiring innovation and technological developments.

Polyhydroxyalkanoates (PHAs) are a family of biodegradable polyesters synthesized by various types of microorganisms. Taking advantage of the diversity of microorganisms, PHAs can be produced from a variety of materials depending on the ability of the PHA producing strains. A good starting point is to link the production of biodegradable PHAs with the rapidly emerging bioenergy industries, including the use of organic waste from biodiesel production. This strategy takes the principle of life cycle assessment into consideration. The proposed use of waste residue is advantageous from the viewpoint of the life cycle of the microorganism used because it removes the direct effect of PHA production on land usage for agriculture, raw materials such as human food and animal feeds, $\mathrm{CO}_{2}$ emissions from agricultural activities and the use of chemicals for farming [3-5]. However, there is a big gap between economic drivers and societal perceptions that will promote or hinder advancements in the use of wastes as resources for a bio-based society.

Crude glycerol is an organic waste from biodiesel production. The increasing amount of biodiesel production has generated crude glycerol residues with a $98 \%$ conversion yield, resulting in $1 \mathrm{~kg}$ of crude glycerol produced for every $10 \mathrm{~kg}$ of biodiesel manufactured [6]. The dramatic rise in the world's biodiesel production has resulted in a large surplus of crude glycerol production and its limited market size has resulted in a decrease in its price. Crude glycerol is of low-impact economic value because of the presence of various impurities such as methanol, soap, free fatty acids, fatty acid methyl esters, and spent catalyst residues. Nowadays, there are a growing number of attempts to develop chemical processes and bioprocesses for the value-added conversion of crude glycerol [7-9].
The development of a bioconversion system to convert crude glycerol residue to higher value-added products is urgently needed and an opportunity to overcome the negative impact of low prices of crude glycerol. Thus, microbial fermentation to convert crude glycerol to useful chemicals such as PHAs is an attractive solution. In general, almost all biodiesel is produced from vegetable oils. In Brazil, a world leader in biofuels, a range of oils, including soybean, sunflower, castor oil, and Jatropha curcas are used, while in Europe the majority of biodiesel is produced from rapeseed oil. However, used cooking oils are becoming increasingly popular as starting materials because of their lower cost, because they are not a human food resource, and to reduce problems in municipal waste management, etc. [10]. The chemical composition of crude glycerol is highly variable with different types of catalysts and starting materials used for biodiesel production [9]. Hansen et al. (2009) analyzed the chemical composition of 11 types of crude glycerol obtained from seven Australian biodiesel manufacturers and revealed that the glycerol content in crude glycerol varied from $38-96 \%$, and up to $16.1 \%$ methanol was present as an impurity [11]. Moreover, Hu et al. (2012) reported that crude glycerol obtained during biodiesel preparation from waste vegetable oil contained glycerol 28.9 (wt \%), an organic fraction 52.3 (wt \%), and $8.6 \%$ methanol. The aqueous fraction consisted mainly of glycerol, methanol and water, and the organic fraction contained fatty acid methyl esters, free fatty acids, and glycerides [12].

The objective of this work was to search for new bacteria capable of utilizing crude glycerol obtained from the biodiesel industry in Thailand, where the starting material for the biodiesel reaction is used-cooking oils, for growth and PHA production. Our efforts in screening new bacterial strains capable of using the crude glycerol directly for PHA production are reported. We discuss the biosynthesis and characterization of medium chain length (mcl)-PHAs and the context for PHA production.

\section{Results and discussion}

\section{Morphological and taxonomical identification}

A total of 20 isolates were obtained from soil that was contaminated with used-cooking oil using enrichment methods, and these isolates were able to grow on medium containing crude glycerol from the biodiesel industry. Using the methods described in "Methods" section for screening PHA producing bacteria, four different strains showed positive results, defined as exhibiting the accumulation of poly-3-hydroxybutyrate (PHB) granules; these strains were named ASC1, ASC2, ASC3 and ASC4, respectively. The physiological and biochemical characteristics of these strains were examined (Table 1). Colonies of ASC1 on nutrient agar plates were small, circular, 
Table 1 Characterization of isolated PHA producing strains by biochemical tests

\begin{tabular}{|c|c|c|c|c|}
\hline \multirow[t]{2}{*}{ Biochemical test } & \multicolumn{4}{|c|}{ Results } \\
\hline & ASC1 & ASC2 & ASC3 & ASC4 \\
\hline Motility & - & + & + & + \\
\hline Oxidase & - & + & - & + \\
\hline Catalase & + & + & + & + \\
\hline Indole production & - & - & - & - \\
\hline Methyl red & - & - & - & - \\
\hline Voges-Proskauer & - & - & + & - \\
\hline Citrate (simmons) & + & + & + & + \\
\hline Triple sugar iron (TSI) reaction & $\mathrm{K} / \mathrm{K}$ & $\mathrm{K} / \mathrm{K}$ & $A / A$ & KA \\
\hline $\mathrm{H}_{2} \mathrm{~S}$ production (TSI) & - & - & - & - \\
\hline Lysine decarboxylase & - & - & - & + \\
\hline Ornithine decarboxylase & + & + & + & + \\
\hline Urease & - & - & + & + \\
\hline Nitrate reduction & + & + & + & - \\
\hline
\end{tabular}

K/K alkaline slant/alkaline butt $=$ peptone was used and no carbohydrates were fermented, $A / A$ acid slant/acid butt $=$ glucose, lactose and sucrose were fermented, $K / A$ alkaline slant/acid butt $=$ only glucose was fermented and peptone was used

slightly convex with entire margins, opaque and moist. The bacterium ASC1 was Gram-negative with a short rod shape, non-spore forming and non-motile. Colonies of ASC2 on nutrient agar plates were circular with entire margins, light-yellow and shiny. The bacterium ASC2 was Gram-negative, rod-shaped, motile and non-spore forming. Colonies of ASC3 were medium sized, circular with entire margins, opaque and moist. The bacterium ASC3 was Gram-negative, rod-shaped, motile and nonspore forming. Colonies of ASC4 on nutrient agar plates were irregular, opaque and large with undulated margins. The bacterium ASC4 was Gram-positive, rod-shaped, motile and spore-forming. All four strains grew aerobically and were capable of growth at 30 and $37{ }^{\circ} \mathrm{C}$. They were positive in tests for catalase, citrate utilization and ornithine decarboxylase. Only strain ASC3 was able to grow on MacConkey medium, where it reduced lactose and exhibited pink colonies. Strain ASC4 gave a positive result for lysine decarboxylase but could not reduce nitrate.

Physiological and biochemical analysis alone is not sufficient for the accurate characterization of bacteria. To identify these strains, their $16 S$ rDNA genes were amplified by PCR using genomic DNA as the template. The partial sequences of the $16 S \mathrm{rDNA}$ genes of the strains ASC1 (1536 bp), ASC2 (1465 bp), ASC3 (1453 bp) and ASC4 (1503 bp) were submitted to the GenBank sequence database [GenBank: GU227612, GU227613, GU227614, GU227615]. According to a phylogenic analysis, the nucleotide sequence of the DNA fragment encoding the $16 \mathrm{~S}$ rDNA gene of strain ASC1 clearly demonstrated that the closet matches belonged to the genus Acinetobacter, with the highest identity (94.9\%) to A. baumannii strain RM4 [GenBank: FJ855135]. Figure 1a shows a phylogenetic tree generated by the neighborjoining method. The neighbor-joining analysis of the $16 \mathrm{~S}$ $r D N A$ gene was rooted by referring to a gammaproteobacterium (Pseudomonas oleovorans) and comparing among Acinetobacter spp. with a bootstrap support value of $100 \%$. The strain ASC1 was identified as Acinetobacter sp. and named Acinetobacter sp. ASC1. Strain ASC2 belonged to the genus Pseudomonas, with the highest identity $(99.2 \%)$ to P. mendocina strain DS0601-FX [GenBank: FJ840535]. A phylogenetic tree generated by the neighbor-joining method is shown in Fig. 1b. Strain ASC2 was identified as Pseudomonas sp. and named Pseudomonas sp. ASC2. Strain ASC3 belonged to the genus Enterobacter, with the highest identity (99.2 \%) to Enterobacter sp. strain BSRA2 [GenBank: FJ868806] (Fig. 1c). Strain ASC3 was identified as Enterobacter sp. and named Enterobacter sp. ASC3. Strain ASC4 belonged to the genus Bacillus, with the highest identity (98.4\%) to B. subtilis strain IAM 12118T [GenBank: AB042061]. See Fig. 1d for a phylogenetic tree. Strain ASC4 was identified as Bacillus sp. and named Bacillus sp. ASC4.

There have been an increasing number of reports in recent years regarding the use of glycerol as a substrate for PHA production. Most researchers have reported the use of pure glycerol for PHA production, while others have reported on microbial strains that utilize crude glycerol from the biodiesel industry without purification such as the removal of methanol or other impurities. Ashby et al. (2004) reported that P. oleovorans NRRL B-14682 and P. corrugata 388 were able to produce PHA (total cell dry mass of $1.3 \mathrm{~g} / \mathrm{L}$ with $13-27$ wt \% PHA content and $2.1 \mathrm{~g} / \mathrm{L}$ with $42 \%$ PHA, respectively) from crude glycerol biodiesel byproduct containing glycerol, free fatty acids and fatty acid methyl esters in shaken-flask experiments [13]. Ibrahim and Steinbüchel (2009) achieved a high cell-density and PHA productivity (81.2 g/L cell dry mass with 66.9 wt \% PHB content) using Zobellella denitrificans MW1 [14]. Cavalheiro et al. (2009) reported on PHB production from crude glycerol by Cupriavidus necator DSM 545. In that study, a maximum cell dry mass of $82.5 \mathrm{~g} / \mathrm{L}$ was obtained using pure glycerol with a $38 \mathrm{wt} \%$ PHB content $(31.4 \mathrm{~g} / \mathrm{L})$. A lower cell dry mass of $68.8 \mathrm{~g} / \mathrm{L}$ was observed with crude glycerol $(14.7 \mathrm{~g} / \mathrm{L})$ but it had the same percentage PHB content [15]. Kawata and Aiba (2010) obtained cell dry mass of $4.1 \mathrm{~g} / \mathrm{L}$ with a $19 \mathrm{wt} \%$ PHB content in batch cultures Halomonas sp. KM-1 using $3 \%$ crude glycerol [16]. Ibrahim and Steinbuchel (2010) isolated and identified a new PHA accumulating strain of the genus Zobellella which 


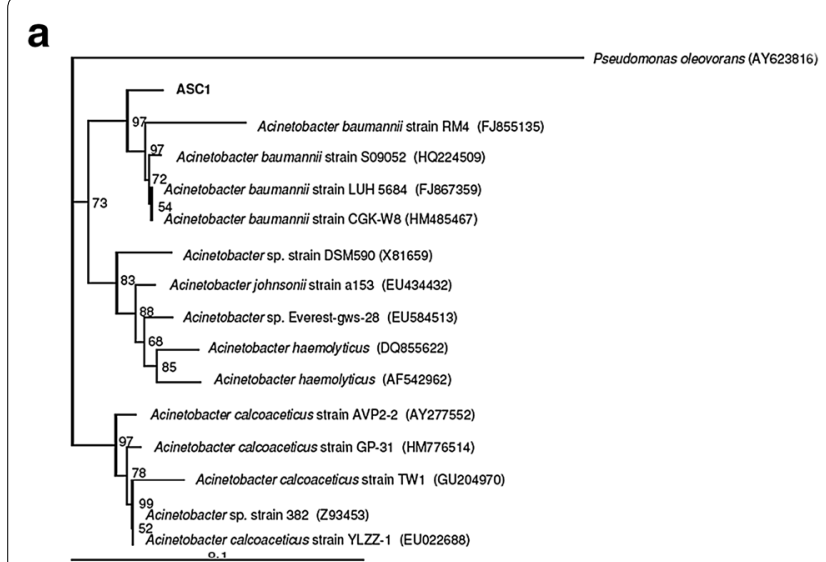

b
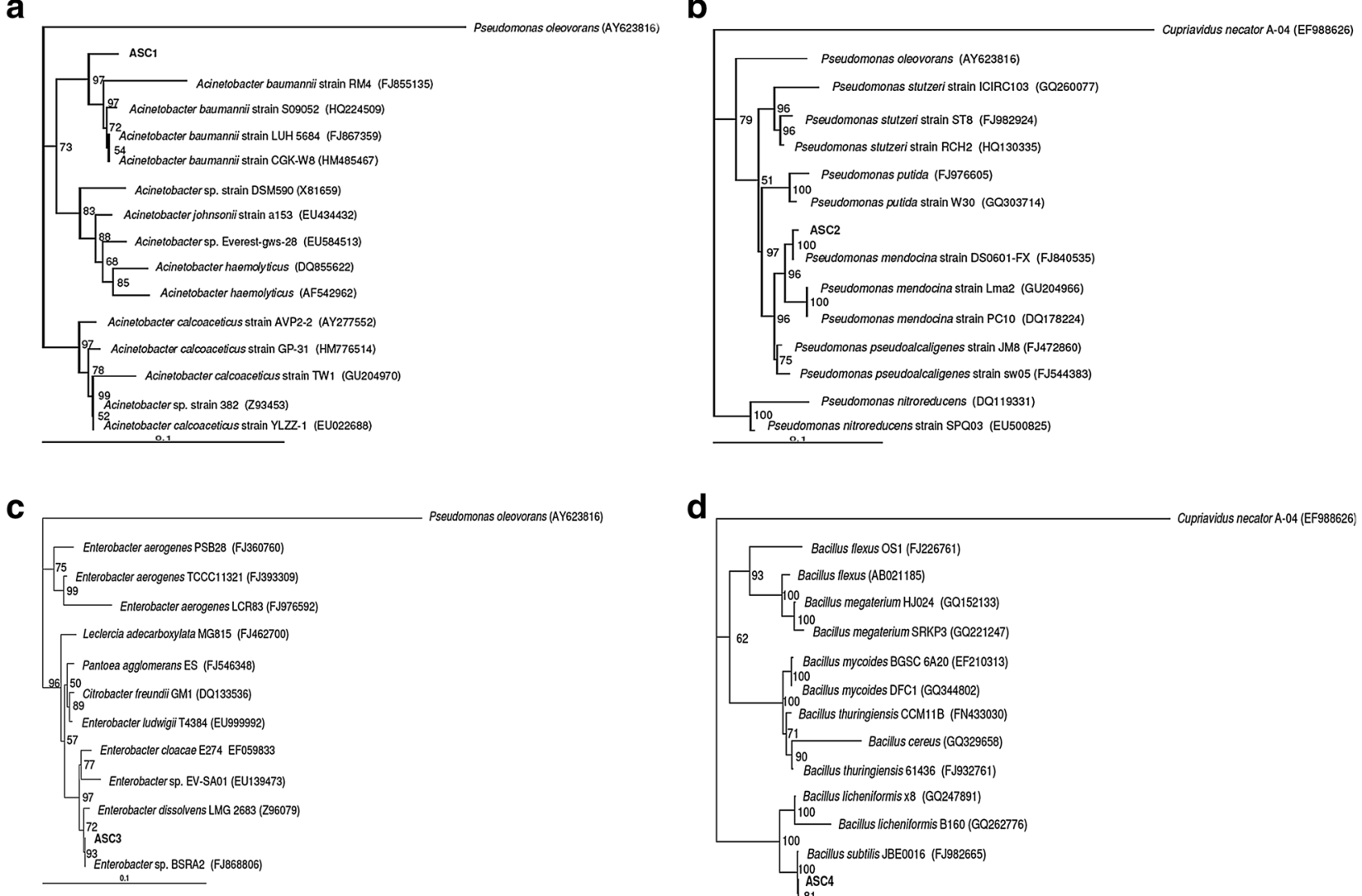

d

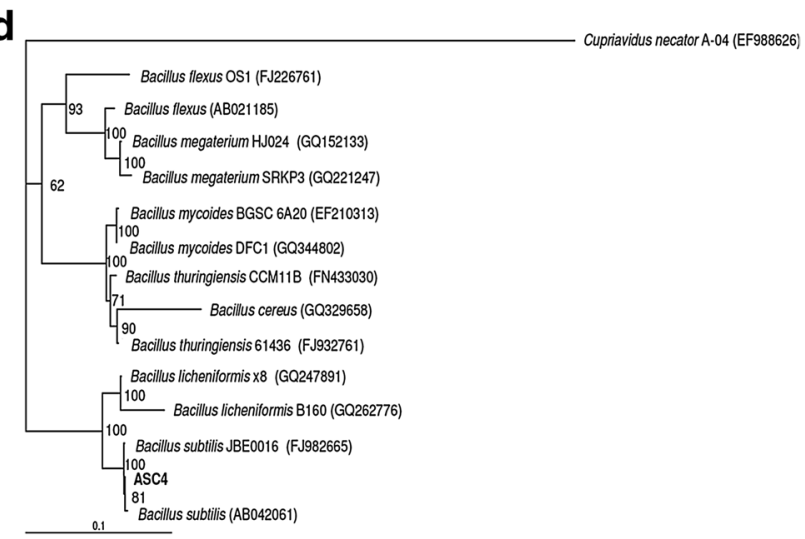

Fig. 1 Phylogenetic tree constructed based on 16S rDNA sequences. a Acinetobacter sp. ASC1. b Pseudomonas sp. ASC2. c Enterobacter sp. ASC3. d Bacillus sp. ASC4. The trees were constructed by the neighbor-joining method and rooted by referring to Pseudomonas oleovorans or Cupriavidus necator A-04. The numbers at branches refer to the percentage confidence estimated by a bootstrap analysis with 100 replications. The analysis was performed by including 165 rDNA gene sequences from GenBank (accession numbers indicated in parentheses). Bar $=0.1$ estimated substitutions per sequence position

was able to use glycerol for growth [14]. Recently, Pappalardo et al. (2014) reported that P. mediterranea 9.1 could produce mcl-PHAs from partially refined glycerol, but it only reached a cell dry mass of $3 \mathrm{~g} / \mathrm{L}$ with $21 \mathrm{wt} \%$ PHA content after $72 \mathrm{~h}$ [17]. Thus, the abilities of our isolated strains in growth and biosynthesis of PHAs from glucose, refined glycerol, crude glycerol and various cooking oils were tested in subsequent experiments.

\section{The ability of isolated bacterial strains in growth and biosynthesis of PHAs using glucose, refined glycerol, crude glycerol or various cooking oils}

For this study, crude glycerol and refined glycerol were obtained from a biodiesel plant that uses cooking oils as raw material. Figure 2 shows a brief scheme of the biodiesel production from used cooking oils. The composition of refined glycerol was determined by Witcorp Products Ltd. (Thailand). The crude glycerol was subjected to analysis of chemical composition, including glycerol, methanol and free fatty acid content, by HPLC and GC analyses. Summaries of the chemical compositions of the refined glycerol and crude glycerol used in this study are shown in Table 2. It was clear that the refined glycerol, and also the crude glycerol, contained heavy metals and arsenic that limit their pharmaceutical and food applications. Therefore, to solve the waste management issues, we aimed to use microbial conversion to convert the crude glycerol to value-added chemicals without a requirement for refining steps.

Microbial growth and PHA accumulation studies were preliminarily carried out using glucose, refined glycerol, crude glycerol and various cooking oils: canola oil, palm oil, soybean oil, sunflower oil, corn oil, grape seed oil, olive oil, rice bran oil, and camellia seed oil. First, cells were cultured in production medium with $20 \mathrm{~g} / \mathrm{L}$ carbon source and a carbon to nitrogen $(\mathrm{C} / \mathrm{N})$ ratio of 200 for $72 \mathrm{~h}$ at $30{ }^{\circ} \mathrm{C}$ on a rotary shaker. Table 3 shows the results. All of the bacterial strains could grow on glucose, 


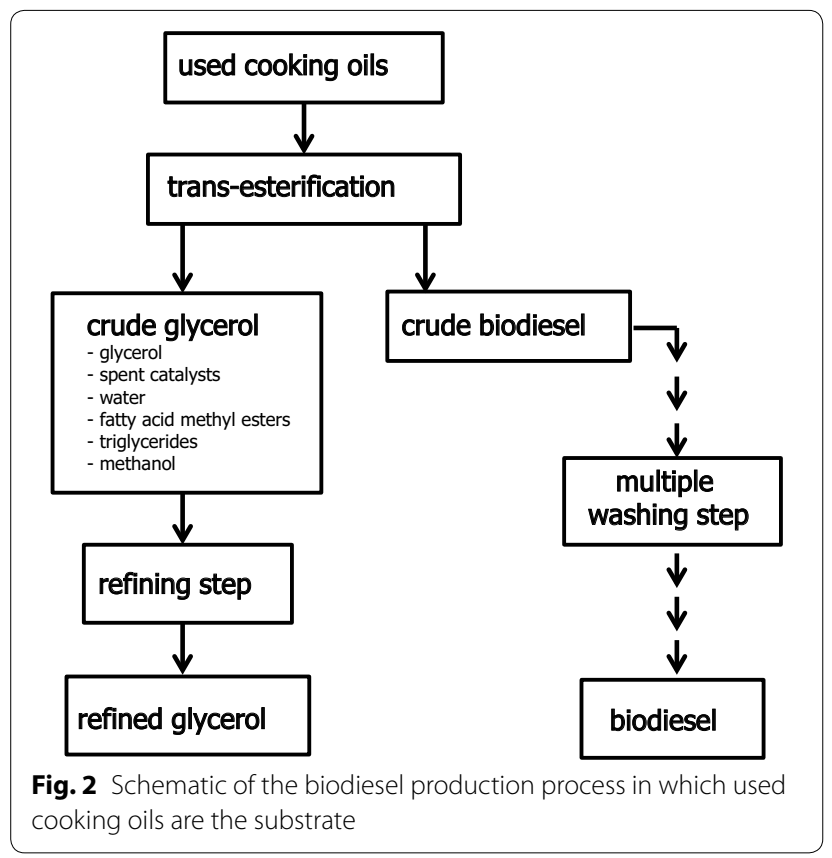

Table 2 Compositions of refined glycerol and crude glycerol

\begin{tabular}{|c|c|c|}
\hline Analysis & Result & Analytical methods \\
\hline \multicolumn{3}{|l|}{ Refined glycerol } \\
\hline Glycerol content & 99.5 wt \% Min & A.O.C.S. Ea 7-50 \\
\hline Specific gravity & $1.26 \mathrm{Min}$ & A.O.C.S. Ea 7-50 \\
\hline Color (APHA) & $10 \operatorname{Max}$ & Lovibond \\
\hline Heavy metal & 5 ppm Max & BS 5711: Part 15 \\
\hline Water content & 0.5 wt $\%$ Max & Karl fisher \\
\hline Combustibles & 0.01 wt $\%$ Max & USP-30 \\
\hline Arsenic & 1.5 ppm Max & BS 5711: Part 10 \\
\hline Diethylene glycol & 0.1 wt $\%$ Max & USP-30 \\
\hline Sulfate & 0.002 wt $\%$ Max & USP-30 \\
\hline Iron & 10 ppm Max & USP-31 \\
\hline \multicolumn{3}{|l|}{ Crude glycerol } \\
\hline Total organic carbon & $300.9 \mathrm{~g} / \mathrm{L}$ & Total organic carbon analyzer \\
\hline Glycerol content & 50.2 wt $\%$ & HPLC \\
\hline Methanol content & 12.0 wt \% & GC \\
\hline Organic fraction & 38.4 wt $\%$ & GC \\
\hline Lauric acid $\left(\mathrm{C}_{12: 0}\right)$ & 1.0 wt $\%$ & $\mathrm{GC}$ \\
\hline Palmitic acid $\left(C_{16: 0}\right)$ & 5.4 wt $\%$ & GC \\
\hline Stearic acid $\left(\mathrm{C}_{18: 0}\right)$ & 0.6 wt $\%$ & GC \\
\hline Oleic acid $\left(C_{18: 1}\right)$ & 11.9 wt \% & GC \\
\hline Linoleic acid $\left(\mathrm{C}_{18: 2}\right)$ & 17.7 wt \% & GC \\
\hline Linolenic acid $\left(\mathrm{C}_{18: 3}\right)$ & 1.8 wt $\%$ & GC \\
\hline
\end{tabular}

but only small quantity of biomass and PHA accumulation was observed; the type of PHA produced was PHB. Next, refined glycerol was examined as the carbon source for growth and PHA production. The highest total cell dry mass, $10.0 \pm 0.9 \mathrm{~g} / \mathrm{L}$, was obtained for Pseudomonas sp. ASC2; however, only $3.9 \pm 0.2 \mathrm{wt} \%$ of PHA was obtained. The composition of PHA produced from refined glycerol consisted of $93 \mathrm{~mol} \%$ 3-hydroxyoctanoate (3HO) and $7 \mathrm{~mol} \% 3$-hydroxy-5-cis-dedecanoate (3H5DD) [P(93\% 3HO-co-7 \% 3H5DD)]. For comparison with refined glycerol, crude glycerol was used as the carbon source in the same cultivation conditions. A similar cell dry mass was obtained as on use of refined glycerol, but higher PHA accumulation was observed. The crude glycerol consisted of glycerol $50.2 \mathrm{wt} \%$, methanol 12.0 wt \%, lauric acid $\left(\mathrm{C}_{12: 0}\right) 1.0 \mathrm{wt} \%$, palmitic acid $\left(\mathrm{C}_{16: 0}\right) 5.4$ wt \%, stearic acid $\left(C_{18: 0}\right) 1.6$ wt \%, oleic acid $\left(C_{18: 1}\right) 11.9$ wt \%, linoleic acid $\left(\mathrm{C}_{18: 2}\right) 17.7 \mathrm{wt} \%$, linolenic acid $\left(\mathrm{C}_{18: 3}\right)$ 1.8 wt \%, and residual cooking oils. Crude Glycerol and the fatty acids listed above were used as precursors for PHA production. The various cooking oils were tested for growth and PHA accumulation. Palm oil concentration of $40 \mathrm{~g} / \mathrm{L}$ gave the highest cell dry mass and PHA content. Canola oil and rice bran oil also promoted cell growth, but less PHA accumulation. It has been reported that the fatty acid composition in palm oil consists of lauric acid $\left(\mathrm{C}_{12: 0}\right) 0.1 \mathrm{wt} \%$, palmitic acid $\left(\mathrm{C}_{16: 0}\right) 45 \mathrm{wt} \%$, oleic acid $\left(\mathrm{C}_{18: 1}\right) 40.5 \mathrm{wt} \%$ and linoleic acid $\left(\mathrm{C}_{18: 2}\right) 10.1 \mathrm{wt} \%$ $[18,19]$. Thus, from crude glycerol, cells used glycerol and several fatty acids for cell growth, and medium chain fatty acids as the precursors for PHA production.

\section{Effect of crude glycerol concentration and the ratio of carbon to nitrogen}

Next, bioreactor cultivation was performed in batch mode for Acinetobacter sp. ASC1, Pseudomonas sp. ASC2, Enterobacter sp. ASC3 and Bacillus sp. ASC4, respectively, to investigate in detail the accumulation of PHAs using crude glycerol as the carbon source. The concentration of crude glycerol was defined as the total organic carbon concentration (TOC). Initial TOC concentrations varied between 5 and $20 \mathrm{~g} / \mathrm{L}$, and $\mathrm{C} / \mathrm{N}$ was set at 200 . The total cell dry mass $(\mathrm{CDM})(\mathrm{g} / \mathrm{L})$, residualcell mass (RCM) (calculated by subtracting the amount of PHA from the total cell dry mass; $g / \mathrm{L})$, PHA content (\%), specific growth rate $[\mu,(1 / \mathrm{h})]$, specific production rate $[\rho$, (g PHA/g CDM/h)], yield coefficient of PHA produced/g residual-cell mass $\left[\mathrm{Y}_{\mathrm{P} / \mathrm{X}},(\mathrm{g} \mathrm{PHA} / \mathrm{g} \mathrm{RCM})\right]$ and productivity (g PHA/(L.h)) were determined (Table 4). The $\mathrm{C} / \mathrm{N}$ 
Table 3 PHA production by isolated strains grown on glucose, refined glycerol, crude glycerol or cooking oils

\begin{tabular}{|c|c|c|c|c|c|c|c|c|}
\hline \multirow[t]{2}{*}{ Substrate } & \multicolumn{2}{|c|}{ Acinetobacter sp. ASC1 } & \multicolumn{2}{|c|}{ Pseudomonas sp. ASC2 } & \multicolumn{2}{|c|}{ Enterobacter sp. ASC3 } & \multicolumn{2}{|c|}{ Bacillus sp. ASC4 } \\
\hline & $\operatorname{CDM}(g / L)$ & PHAs (wt \%) & $\mathrm{CDM}(\mathrm{g} / \mathrm{L})$ & PHAs (wt \%) & $\operatorname{CDM}(g / L)$ & PHAs (wt \%) & CDM (g/L) & PHAs (wt \%) \\
\hline Glucose & $2.7 \pm 0.1$ & $8.2 \pm 3.5$ & $2.2 \pm 0.1$ & $21.7 \pm 2.6$ & $2.6 \pm 0.2$ & $16.8 \pm 1.9$ & $4.8 \pm 0.4$ & $18.9 \pm 1.5$ \\
\hline Refined glycerol & $8.6 \pm 0.1$ & $3.7 \pm 2.4$ & $10.0 \pm 0.2$ & $3.9 \pm 0.9$ & $7.2 \pm 0.1$ & $14.1 \pm 2.7$ & $6.1 \pm 0.2$ & $6.7 \pm 2.8$ \\
\hline Crude glycerol & $8.5 \pm 0.2$ & $25.4 \pm 3.1$ & $10.7 \pm 0.1$ & $28.2 \pm 1.2$ & $9.8 \pm 0.3$ & $33.7 \pm 1.3$ & $7.8 \pm 0.1$ & $34.4 \pm 3.4$ \\
\hline Canola oil & $9.0 \pm 0.1$ & $2.2 \pm 3.2$ & $12.1 \pm 0.2$ & $2.4 \pm 2.0$ & $9.2 \pm 0.1$ & $1.8 \pm 1.4$ & $9.5 \pm 0.2$ & $2.5 \pm 1.1$ \\
\hline Palm oil & $13.3 \pm 0.4$ & $14.2 \pm 3.5$ & $17.8 \pm 0.3$ & $5.5 \pm 1.2$ & $12.1 \pm 0.1$ & $12.0 \pm 2.2$ & $14.6 \pm 0.3$ & $12.1 \pm 2.0$ \\
\hline Soybean oil & $5.8 \pm 0.3$ & $6.7 \pm 2.0$ & $9.7 \pm 0.1$ & $5.6 \pm 2.2$ & $8.1 \pm 0.2$ & $5.3 \pm 1.8$ & $6.6 \pm 0.1$ & $3.4 \pm 1.3$ \\
\hline Sunflower oil & $8.4 \pm 0.1$ & $7.3 \pm 2.1$ & $7.2 \pm 0.1$ & $2.5 \pm 1.8$ & $6.5 \pm 0.3$ & $5.5 \pm 2.0$ & $7.9 \pm 0.1$ & $4.7 \pm 0.9$ \\
\hline Corn oil & $5.9 \pm 0.2$ & $4.1 \pm 1.7$ & $5.1 \pm 0.1$ & $2.6 \pm 1.5$ & $5.2 \pm 0.1$ & $3.1 \pm 1.4$ & $5.8 \pm 0.3$ & $2.2 \pm 1.0$ \\
\hline Grape seed oil & $5.3 \pm 0.1$ & $7.4 \pm 1.9$ & $10.2 \pm 0.2$ & $5.6 \pm 2.5$ & $6.1 \pm 0.1$ & $6.3 \pm 1.0$ & $6.2 \pm 0.1$ & $5.1 \pm 1.3$ \\
\hline Olive oil & $5.3 \pm 0.1$ & $5.0 \pm 1.0$ & $5.3 \pm 0.1$ & $3.7 \pm 0.8$ & $4.3 \pm 0.2$ & $2.1 \pm 0.8$ & $5.0 \pm 0.1$ & $3.2 \pm 0.7$ \\
\hline Rice bran oil & $9.9 \pm 0.1$ & $5.1 \pm 1.2$ & $17.0 \pm 0.2$ & $5.9 \pm 1.9$ & $10.1 \pm 0.1$ & $4.8 \pm 1.1$ & $12.5 \pm 0.1$ & $6.0 \pm 1.5$ \\
\hline Camellia seed oil & $5.7 \pm 0.1$ & $3.4 \pm 1.1$ & $5.5 \pm 0.1$ & $3.3 \pm 1.1$ & $4.8 \pm 0.1$ & $2.9 \pm 0.6$ & $3.7 \pm 0.1$ & $2.2 \pm 0.2$ \\
\hline
\end{tabular}

Bacteria were cultured in production medium with $20 \mathrm{~g} / \mathrm{L}$ carbon source at a carbon to nitrogen ratio of 200 for $72 \mathrm{~h}$ at $30{ }^{\circ} \mathrm{C}$ on a rotary shaker. The dry cell mass was assayed by GC analysis. All data are expressed as \pm SD and represent the mean value of three parallel experiments

CDM cell dry mass ( $\mathrm{g} / \mathrm{L})$, PHA total PHA content (wt \%)

Table 4 Kinetic study of the effect of total organic carbon (TOC) concentration

\begin{tabular}{|c|c|c|c|c|c|c|}
\hline $\mathrm{TOC}(\mathrm{g} / \mathrm{L})$ & $\begin{array}{l}\text { CDM } \\
(g / L)\end{array}$ & $\begin{array}{l}\text { PHA } \\
\text { Content (wt \%) }\end{array}$ & $\begin{array}{l}\text { Yield } \\
\text { (g PHA/g RCM) }\end{array}$ & $\begin{array}{l}\mu \\
(1 / h)\end{array}$ & $\begin{array}{l}\rho \\
(\mathrm{g} \mathrm{PHA} / \mathrm{g} \text { CDM/h) }\end{array}$ & $\begin{array}{l}\text { Productivity } \\
\text { [g PHA/(L h)] }\end{array}$ \\
\hline \multicolumn{7}{|l|}{ TOC $5 \mathrm{~g} / \mathrm{L}$} \\
\hline Acinetobacter sp. ASC1 & $12.0 \pm 0.1$ & $15.6 \pm 1.7$ & 0.19 & 0.033 & 0.007 & 0.05 \\
\hline Pseudomonas sp. ASC2 & $12.2 \pm 0.2$ & $22.4 \pm 2.4$ & 0.29 & 0.031 & 0.012 & 0.08 \\
\hline Enterobacter sp. ASC3 & $13.0 \pm 0.2$ & $18.5 \pm 3.2$ & 0.23 & 0.035 & 0.009 & 0.07 \\
\hline Bacillus sp. ASC4 & $8.7 \pm 0.3$ & $33.5 \pm 1.2$ & 0.5 & 0.018 & 0.018 & 0.08 \\
\hline \multicolumn{7}{|l|}{$\mathrm{TOC} 10 \mathrm{~g} / \mathrm{L}$} \\
\hline Acinetobacter sp. ASC1 & $23.5 \pm 0.1$ & $54.6 \pm 3.4$ & 0.49 & 0.023 & 0.014 & 0.36 \\
\hline Pseudomonas sp. ASC2 & $32.3 \pm 0.3$ & $61.8 \pm 3.3$ & 0.65 & 0.047 & 0.022 & 0.55 \\
\hline Enterobacter sp. ASC3 & $33.1 \pm 0.2$ & $47.2 \pm 2.2$ & 0.57 & 0.042 & 0.01 & 0.43 \\
\hline Bacillus sp. ASC4 & $13.2 \pm 0.4$ & $47.4 \pm 1.5$ & 0.51 & 0.022 & 0.017 & 0.17 \\
\hline \multicolumn{7}{|l|}{ TOC $20 \mathrm{~g} / \mathrm{L}$} \\
\hline Acinetobacter sp. ASC1 & $27.3 \pm 0.2$ & $23.4 \pm 2.7$ & 0.31 & 0.023 & 0.014 & 0.18 \\
\hline Pseudomonas sp. ASC2 & $24.2 \pm 0.1$ & $39.4 \pm 1.6$ & 0.58 & 0.044 & 0.03 & 0.27 \\
\hline Enterobacter sp. ASC3 & $27.3 \pm 0.2$ & $30.0 \pm 2.2$ & 0.42 & 0.051 & 0.02 & 0.15 \\
\hline Bacillus sp. ASC4 & $21.8 \pm 0.5$ & $33.8 \pm 2.4$ & 0.41 & 0.023 & 0.023 & 0.2 \\
\hline
\end{tabular}

Cells were grown in production medium with a carbon to nitrogen ratio of 200 in batch cultivation

ratio of 200 represents nitrogen deficient conditions. Figure 3 shows time courses of cell dry mass, mcl-PHAs and TOC concentration on growing Acinetobacter sp. ASC1 (Fig. 3a), Pseudomonas sp. ASC2 (Fig. 3b), Enterobacter sp. ASC3 (Fig. 3c) and Bacillus sp. ASC4 (Fig. 3d) when grown on crude glycerol at the optimal initial TOC concentration of $10 \mathrm{~g} / \mathrm{L}$. Pseudomonas sp. ASC2 (Fig. 3b) and Enterobacter sp. ASC3 (Fig. 3c) started to accumulate mcl-PHAs during the exponential growth phase. The TOC concentration decreased simultaneously with cultivation time. The nitrogen source, ammonium sulfate, was consumed completely after $12 \mathrm{~h}$ of cultivation (data not shown). Pseudomonas sp. ASC2 showed the highest PHA productivity attained in the batch cultures (0.6 g PHA/(L.h)) and the highest total cell dry mass $(32.3 \pm 0.3 \mathrm{~g} / \mathrm{L})$, PHA concentration $(20.0 \pm 0.9 \mathrm{~g} / \mathrm{L})$ and PHA content $(61.8 \pm 3.3 \mathrm{wt} \%)$. Enterobacter sp. ASC3 yielded a similar total cell dry mass $(33.1 \pm 0.3 \mathrm{~g} / \mathrm{L})$ but a lower PHA concentration $(15.6 \pm 0.8 \mathrm{~g} / \mathrm{L})$ and PHA content $(47.2 \pm 2.2 \mathrm{wt} \%)$. 

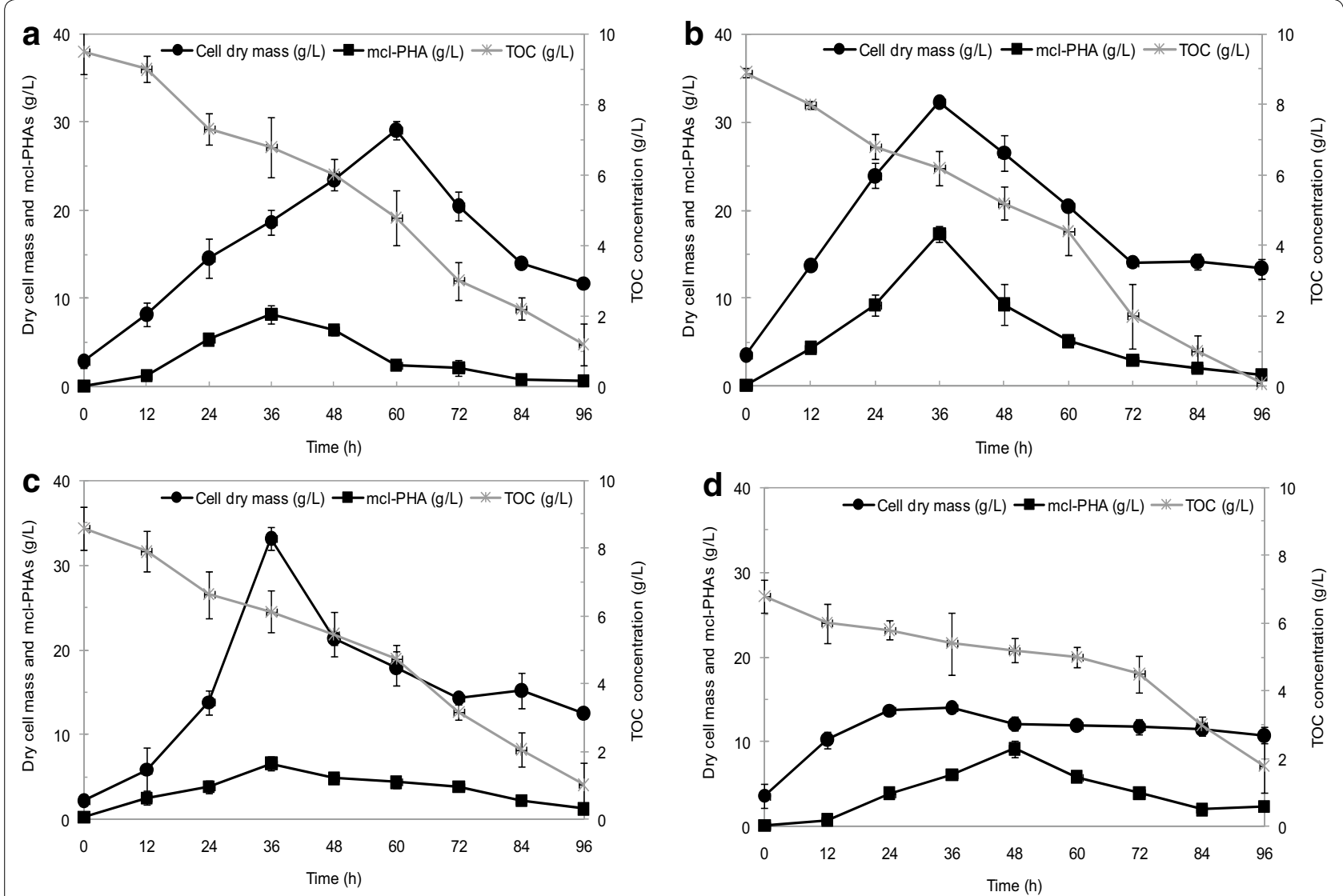

Fig. 3 Time courses of cell dry mass ( $\mathrm{g} / \mathrm{L}$ ), mcl-PHA levels $(\mathrm{g} / \mathrm{L})$ and total organic carbon (TOC) concentration ( $\mathrm{g} / \mathrm{L}$ ) in cultures. a Acinetobacter sp. ASC1. b Pseudomonas sp. ASC2. c Enterobacter sp. ASC3. d Bacillus sp. ASC4. The cells were grown on crude glycerol with a TOC concentration of $10 \mathrm{~g} / \mathrm{L}$ and a C/N ratio of 200 in a bioreactor in batch mode. Cultures were performed in triplicate. The error bars represent standard deviations

Typical cell characteristics of Acinetobacter sp. ASC1, Pseudomonas sp. ASC2, Enterobacter sp. ASC3, Bacillus sp. ASC4, and the PHB granule content in cells, were examined by transmission electron microscopy (TEM). As can be seen in Fig. 4a, Acinetobacter sp. ASC1 cells were coccobacillus rods, $0.4 \mu \mathrm{m}$ in diameter and $0.8-$ $1.0 \mu \mathrm{m}$ in length. PHA granules, numbering approximately 20, accumulated inside the cells. Pseudomonas sp. ASC2 cells were rods, $0.3 \mu \mathrm{m}$ in diameter and $0.6-0.8 \mu \mathrm{m}$ in length, containing a few PHA granules (Fig. 4b). TEM of Enterobacter sp. ASC3 cells (Fig. 4c) showed that they were short rods, $0.3 \mu \mathrm{m}$ in diameter and $0.6 \mu \mathrm{m}$ in length, containing 1-2 PHA granules. The TEM of Bacillus sp. ASC4 (Fig. 4d) revealed that the cells were short rods with $0.4 \mu \mathrm{m}$ diameter and a length of $0.6 \mu \mathrm{m}$. PHA granules were clearly observed.

Next, a TOC concentration of $10 \mathrm{~g} / \mathrm{L}$ was chosen, and the $\mathrm{C} / \mathrm{N}$ ratio was varied $(4,20,80,100$ and 200 , respectively). Figure 5 shows the effect of the change in $\mathrm{C} / \mathrm{N}$ ratio on specific growth rate, $\mu$, and specific PHA production rate, $\rho$, for each bacterial strain. Acinetobacter sp. ASC1 (Fig. 5a) and Bacillus sp. ASC4 (Fig. 5d) attained their highest specific PHA production rates under nitrogen limited conditions $(C / N=200)$, whereas their specific growth rates reached their maximum under nitrogen sufficient conditions. In contrast, Pseudomonas sp. ASC2 (Fig. 5b) and Enterobacter sp. ASC3 (Fig. 5c) produced most PHA during their growth phase between a $\mathrm{C} / \mathrm{N}$ of 4 and 20. These results correspond with the TEM analysis in Fig. 4. At a $\mathrm{C} / \mathrm{N}$ ratio of 200 , Acinetobacter sp. ASC1 (Fig. 4a) and Bacillus sp. ASC4 (Fig. 4d) accumulated many PHA granules, whereas Pseudomonas sp. ASC2 (Fig. 4b) and Enterobacter sp. ASC3 (Fig. 4c) harbored only a few PHA granules.

Based on GC analysis, the PHAs produced were not homopolymer PHB, but a copolymer of mcl-PHAs. Next, the mcl-PHAs were extracted from cells and subjected to chemical characterization. 

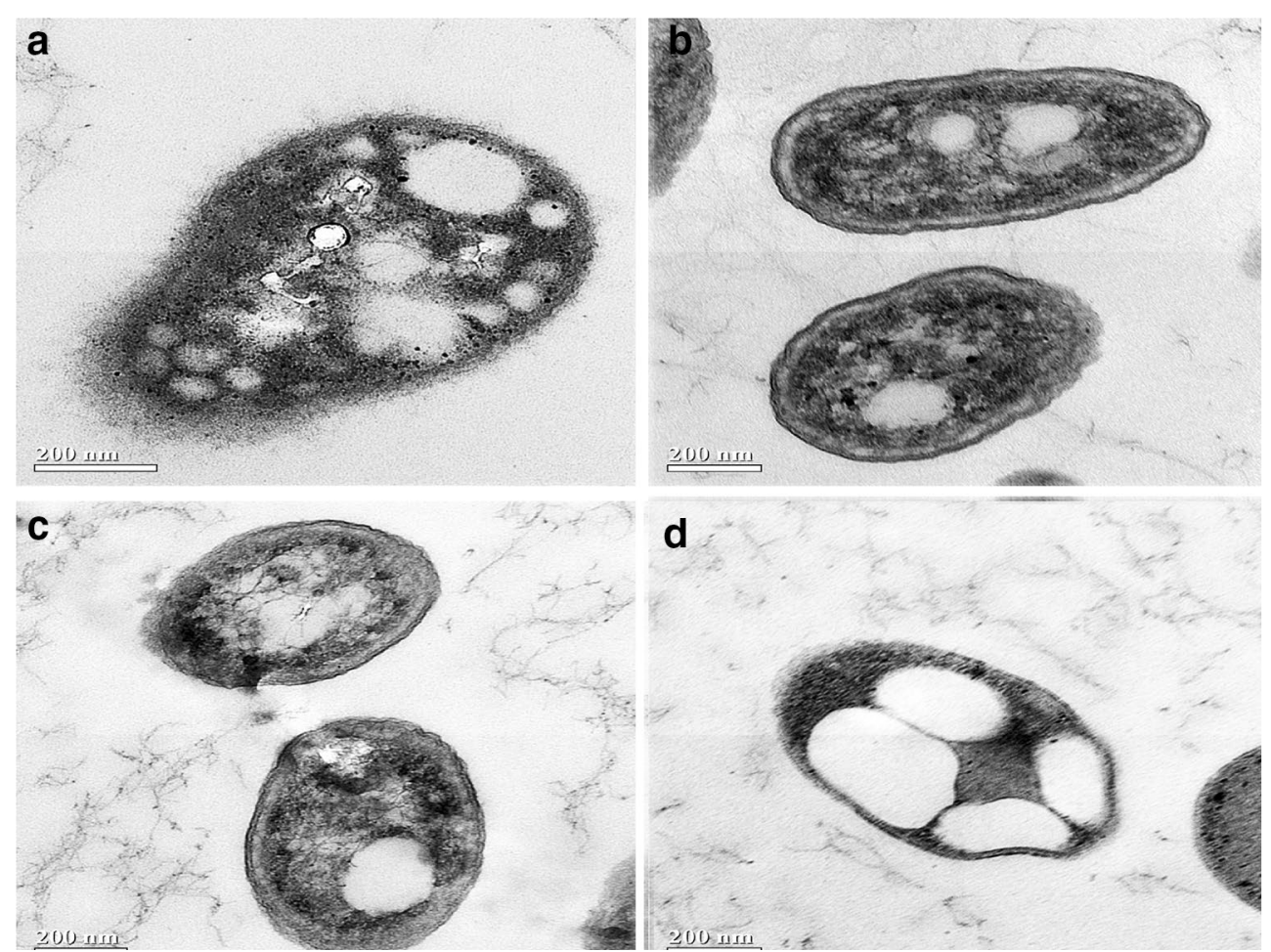

Fig. 4 Transmission electron micrographs of an ultrathin section. a Acinetobacter sp. ASC1. b Pseudomonas sp. ASC2. c Enterobacter sp. ASC3. d Bacillus sp. ASC4. Bars $200 \mathrm{~nm}$

\section{Characterization of mcl-PHAs by GC, ${ }^{1} \mathrm{H}$ NMR, $2 \mathrm{D}-{ }^{1} \mathrm{H}-\mathrm{COSY}$ NMR and ${ }^{13} \mathrm{C}$ NMR analyses}

To ensure an accurate determination of the PHA compositions, $5 \mathrm{~L}$ bioreactor batch cultivations containing $3 \mathrm{~L}$ production medium and an initial TOC concentration of $10 \mathrm{~g} / \mathrm{L}$ with $\mathrm{C} / \mathrm{N}$ ratio of 200 or $\mathrm{C} / \mathrm{N}$ ratio of four depending on the bacterial strain were performed for each strain and the PHAs produced were purified as described in "Methods" section. GC was used to analyze the methyl esters of the monomers, and the 3-hydroxy fatty acid methyl esters were identified by comparison with various standards. Figures 6 and 7 show examples of ${ }^{1} \mathrm{H}$ and $2 \mathrm{D}-{ }^{1} \mathrm{H}-\mathrm{COSY}$ spectra of mcl-PHAs, in this case those produced by Pseudomonas sp. ASC2 on batch cultivation in the bioreactor. NMR peak assignment was carried out according to previous literature [20-22]. The complex multiplet and unsymmetrical triplet observed respectively in regions $a$ and $e$ of the ${ }^{1} \mathrm{H}$ spectrum (Fig. 6) are consistent with the overlap of peaks from monomer units found in all PHA samples. The ${ }^{1} \mathrm{H}$ NMR spectra of all of the PHA samples produced in this work show peaks with almost identical chemical shifts that agreed well with those in previous reports [21, 22]. In Fig. 6, peaks $a$ and $b$ can be assigned to the protons next to the carboxyl group and the ether oxygen, respectively; peak $c$ at $1.6 \mathrm{ppm}$ was assigned to the first $\mathrm{CH}_{2}$ of the side chains; peaks $d$ (at $1.3 \mathrm{ppm}$ ) and $e$ (at $1.0 \mathrm{ppm}$ ) were assigned to remaining side-chain $\mathrm{CH}_{2}$ groups and the $\mathrm{CH}_{3}$ group, respectively. The chemical shifts of peaks $g$ and $h$ indicate the presence of an unsaturated group in some of the monomers. To identify peak $f$ (at $2.0 \mathrm{ppm}$ ) and peak $j$ (at $3.6 \mathrm{ppm}$ ), 2D-COSY- ${ }^{1} \mathrm{H}$ NMR spectroscopy was performed (Fig. 7). In $2 \mathrm{D}-\mathrm{COSY}^{-}{ }^{1} \mathrm{H}$ NMR spectroscopy, cross peaks are present between coupled proton signals belonging to neighboring protons in the structure. A proton can walk through a chemical structure by proton to proton walking within the structure. In this way, the position of a double bound in an unsaturated alkyl chain can be identified. The peak $f$ was assigned to a $\mathrm{CH}_{2}$ group next to a double bond [21]. Overall, this compound was identified as a copolymer consisting of 3-hydroxyoctanoate (3HO) and 3-hydroxy-5-cis-dodecenote (3H5DD) from peak $e$ to peak $a$ via peaks $b, g$ and $h$ in the ${ }^{1} \mathrm{H}$ NMR and 2D-COSY- ${ }^{1} \mathrm{H}$ NMR spectra. Peak $j$ was assumed to arise from impurities from other fatty acids because proton to proton walking through the structure could not be observed.

The PHA samples produced in this work were also studied by ${ }^{13} \mathrm{C}$ NMR. Figure 8 shows the ${ }^{13} \mathrm{C}$ NMR spectrum of poly $(5 \mathrm{~mol} \%$ 3-hydroxyoctanoate- 

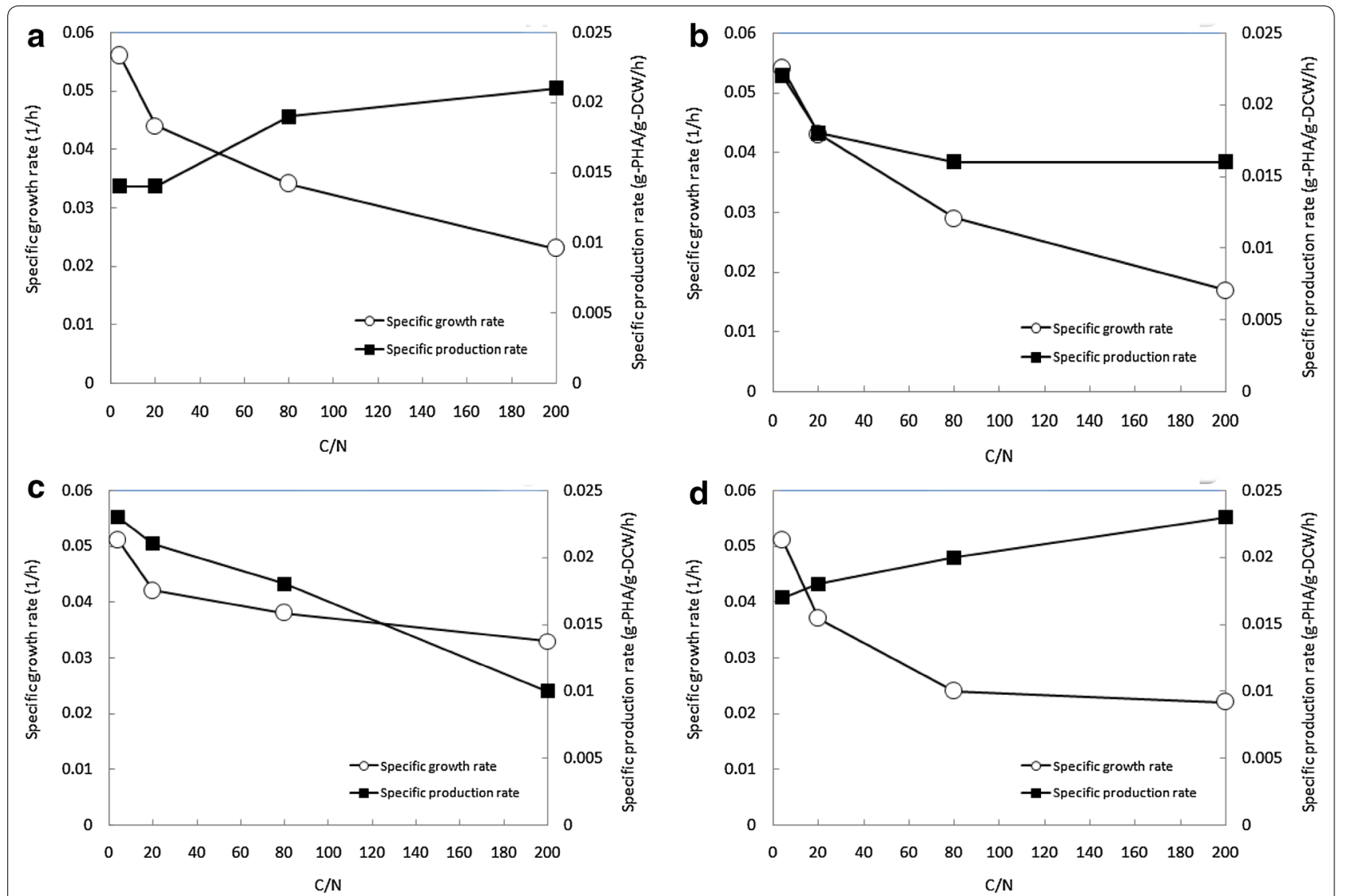

Fig. 5 Effect of the $\mathrm{C} / \mathrm{N}$ ratio on the specific growth rate of bacteria and specific production rate of PHA. a Acinetobacter sp. ASC1. b Pseudomonas sp. ASC2. c Enterobacter sp. ASC3. d Bacillus sp. ASC4

co-95 mol \% 3-hydroxy-5-cis-dedecanoate) [P(5 \% 3HOco-95 \% 3H5DD)] synthesized by Pseudomonas sp. ASC2 from crude glycerol at a TOC concentration of $10 \mathrm{~g} / \mathrm{L}$ and a $\mathrm{C} / \mathrm{N}$ ratio of 200 . The chemical shifts were assigned for each carbon resonance (see Table 5) according to previous reports $[22,23]$. The main chain carbons $\left(\mathrm{C}_{1}-\mathrm{C}_{3}\right.$, see Fig. 8) of the repeating units were assigned by comparison with the chemical shifts of carbons $1-3$ of $\mathrm{HO}$ and $3 \mathrm{H} 5 \mathrm{DD}$ and the values are given in Table 5 (previously reported in the literature $[22,23])$. The chemical shifts at 14 and $31.9 \mathrm{ppm}$ corresponded to the methyl groups of $3 \mathrm{HO}$ at positions $\mathrm{C}_{4}$ and $\mathrm{C}_{5}$ (see Table 5), respectively [23]. The chemical shifts at 129.9 and 128 ppm corresponded to the methyl groups of 3H5DD at positions $\mathrm{C}_{6}$ and $C_{5}$, respectively [22]. The signals at 14 and $129.9 \mathrm{ppm}$ confirmed the predominance of $3 \mathrm{HO}$ and 3H5DD units, thus matching the results of gas chromatography with flame ionization detection (GC-FID) analyses. The monomer composition profile, $3 \mathrm{HO}$ and 3H5DD, (mol \%) analyzed by GC-FID is shown in Fig. 9. An increase of $3 \mathrm{HO}(\mathrm{mol} \%)$ composition with cultivation time was observed for Enterobacter sp. ASC3, whereas a decrease of $3 \mathrm{HO}$ (mol \%) composition was observed for the other species. Homopolymeric 3H5DD was obtained from Bacillus sp. ASC4 when the cultivation time was prolonged to $96 \mathrm{~h}$.

Huijberts et al. (1992) described the accumulation of products by $P$. putida KT2442 during growth on nonrelated substrates such as glucose, fructose and glycerol. In addition to the predominant monomer, 3HD, they observed that two of the monomers, 3-hydroxy-cis-5-dodecanoic acid $\left(\mathrm{C}_{12: 1}\right)$ and 3-hydroxy-cis-7-tetradecenoic acid $\left(\mathrm{C}_{14: 1}\right)$, contained unsaturated bonds [21]. Haywood et al. (1990) and Timm and Steinbuchel (1990) confirmed and extended this observation to show that the ability to accumulate PHA containing 3HD is shared by many Pseudomonas strains [20, 24]. In their studies, P. mendocina DSM 50017, the Pseudomonas species that presents the closest match to Pseudomonas sp. ASC2, could use gluconate as a carbon source and accumulated $50.7 \mathrm{wt} \%$ PHAs containing 3HHx (4.3 mol \%), 3HO (29.8 mol \%), 3HD (61.9 mol \%) and 3HDD (4.2 mol \%). More recently, several research groups have attempted to demonstrate metabolic pathways for Escherichia coli converting 

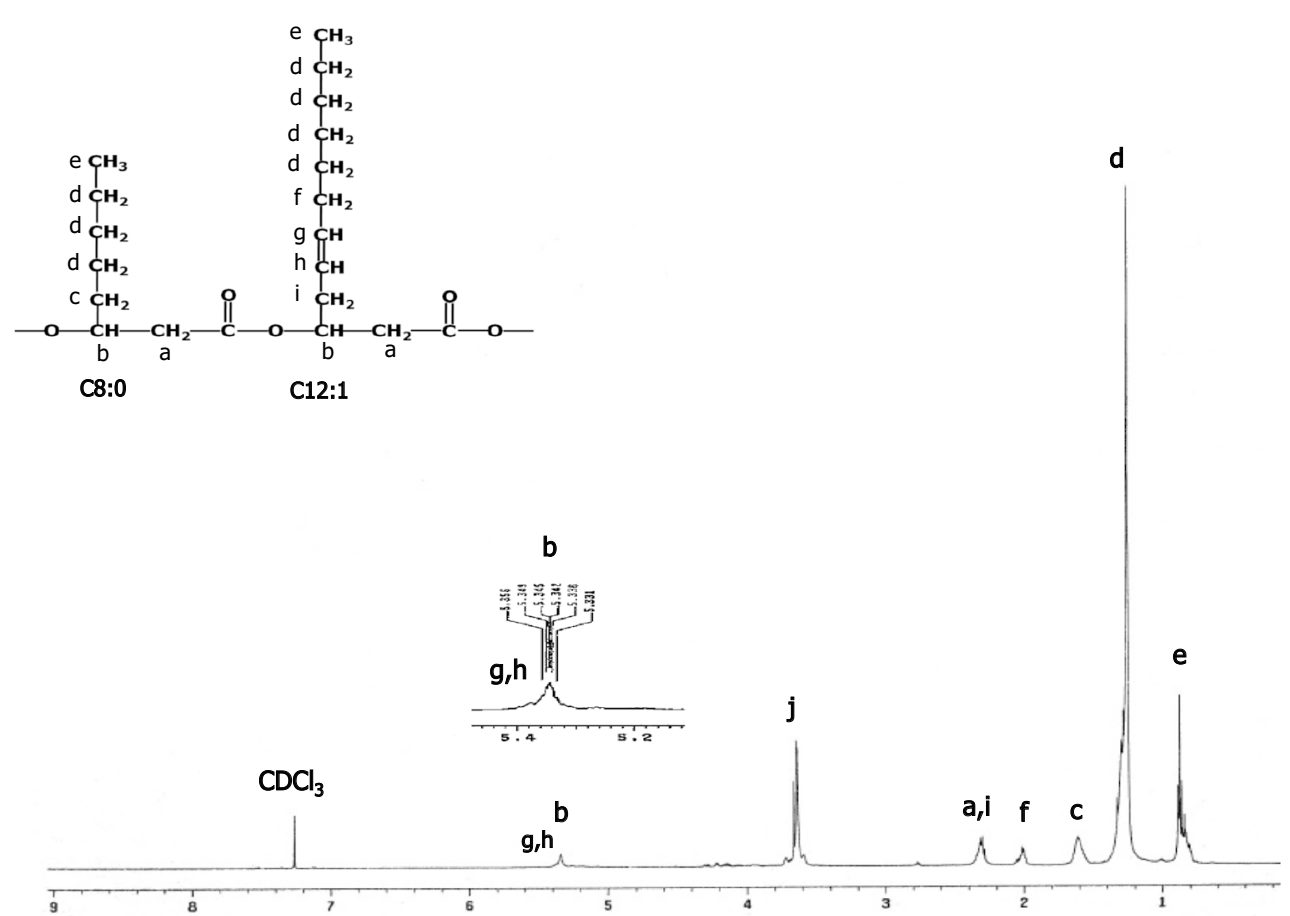

Fig. $6500 \mathrm{MHz}{ }^{1} \mathrm{H}-\mathrm{NMR}$ spectrum of $\mathrm{P}(5 \% 3 \mathrm{HO}-\mathrm{CO}-95 \%$ 3H5DD) synthesized by Pseudomonas sp. ASC2. Crude glycerol with a TOC concentration of $10 \mathrm{~g} / \mathrm{L}$ and a $\mathrm{C} / \mathrm{N}$ molar ratio of 200 were used in the culture. Letters on the spectrum indicate peaks arising from the protons marked in the corresponding structure. 3HO, 3-hydroxyoctanoate; 3H5DD, 3-hydroxy-5-cis-dodecanoate

glucose [25] and P. putida converting relevant fatty acids [26] into mcl-PHAs composed primarily of 3-hydroxydodecanoate monomers.

In the present work, all mcl-PHAs were composed of two main monomers, $3 \mathrm{HO}\left(\mathrm{C}_{8: 0}\right)$ and $3 \mathrm{H} 5 \mathrm{DD}\left(\mathrm{C}_{12: 1}\right)$, suggesting that the degradation pathway of medium chain fatty acid-containing substrates and the PHA synthesis pathway might be similar in all the tested strains. Based on the types of mcl-PHAs produced by the bacterial strains, we suggest that in the crude glycerol, which consists of glycerol $50.2 \mathrm{wt} \%$, methanol $12.0 \mathrm{wt} \%$, small amounts of saturated fatty acids [lauric acid $\left(\mathrm{C}_{12: 0}\right) \quad 1.0$ wt \%, palmitic acid $\left(C_{16: 0}\right) 5.4 \mathrm{wt} \%$, stearic acid $\left(\mathrm{C}_{18: 0}\right) 1.6$ wt \%], and relatively high amounts of unsaturated fatty acids [oleic acid $\left(\mathrm{C}_{18: 1}\right) 11.9 \mathrm{wt} \%$, linoleic acid $\left(\mathrm{C}_{18: 2}\right) 17.7$ wt \%, linolenic acid $\left.\left(\mathrm{C}_{18: 3}\right) 1.8 \mathrm{wt} \%\right]$, the saturated fatty acids could be precursors for $3 \mathrm{HO}\left(\mathrm{C}_{8: 0}\right)$, whereas the unsaturated fatty acids were the precursors for 3H5DD $\left(C_{12: 1}\right)$. However, other medium length chain fatty acids such as $3 \mathrm{HD}-\mathrm{CoA}\left(\mathrm{C}_{10: 0}\right)$ were not observed in this study. It might be that the lack of $3 \mathrm{HD}-\mathrm{CoA}\left(\mathrm{C}_{10: 0}\right)$ was attributable to the $\beta$-oxidation of $\mathrm{C}_{10}$ that generates $3 \mathrm{HO}-\mathrm{CoA}$ $\left(\mathrm{C}_{8: 0}\right)$ and also additional energy. In the presence of glycerol, the conversion of glycerol to acetyl-CoA may be used to generate either biomass or intermediates for the synthesis of mcl-PHAs, resulting in unsaturated medium chain fatty acid conversion to $3 \mathrm{H} 5 \mathrm{DD}\left(\mathrm{C}_{12: 1}\right)$ at a higher level than previously achieved. Based on GC-FID analysis combined with ${ }^{1} \mathrm{H}$ NMR, 2D-COSY- ${ }^{1} \mathrm{H}$ NMR and ${ }^{13} \mathrm{C}$ NMR spectra, we could not observe any monomers other than $3 \mathrm{HO}\left(\mathrm{C}_{8: 0}\right)$ and $3 \mathrm{H} 5 \mathrm{DD}\left(\mathrm{C}_{12: 1}\right)$.

Various factors affect the production of mcl-PHA, including bacterial strains, types of carbon source, cultivation time, environmental conditions, PHA biosynthesis genes, and PHA biosynthesis pathways [27]. For Bacillus sp. and Acinetobacter sp., most reports are based on their ability to produce PHB from sugars and other unrelated carbon sources. Shahid et al. (2013) was the first report to disclose that B. megaterium DSM 509 possessed atypical metabolism resulting in mcl-PHA production from glycerol under conditions of nitrogen limitation. In this study, in specific cultivation conditions, mcl-PHA consisting of 3HB, 3-hydroxyhexanoate (3HHx), 3HO, 3HD, 3-hydroxydodecanoate (3HDD), 3H5DD, and 3-hydroxytetradecanoate (3HTD) was produced [28]. Hwan et al. (2008) also reported based on gas chromatography/mass spectroscopy analysis that Acinetobacter sp. strain DR1 could produce mcl-PHA consisting of $39 \mathrm{~mol} \% 3 \mathrm{HD}$, $52 \mathrm{~mol} \% 3 \mathrm{HDD}$ and $9 \mathrm{~mol} \% 3 \mathrm{HTD}$. Although, there is no literature reporting the biosynthesis pathway for 


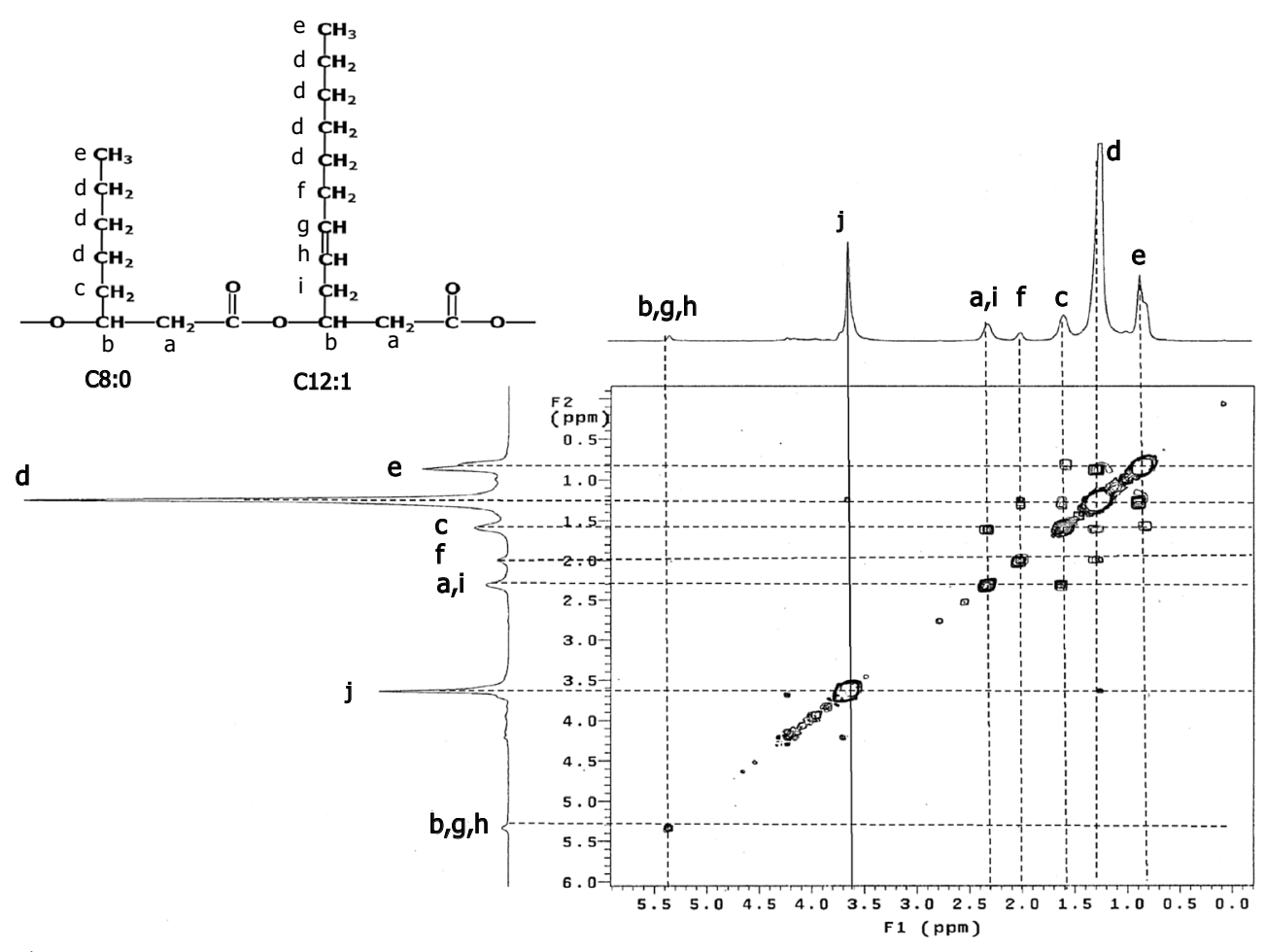

Fig. 7 2D-COSY- ${ }^{1} \mathrm{H}$ NMR spectrum of $\mathrm{P}(5 \% 3 \mathrm{HO}-\mathrm{CO}-95 \% 3 \mathrm{H} 5 \mathrm{DD})$ synthesized by Pseudomonas sp. ASC2. Crude glycerol with a TOC concentration of $10 \mathrm{~g} / \mathrm{L}$ and a $\mathrm{C} / \mathrm{N}$ molar ratio of 200 were used in the culture. Letters on the spectrum indicate peaks arising from the protons marked in the corresponding structure. $3 \mathrm{HO}$, 3-hydroxyoctanoate; 3H5DD, 3-hydroxy-5-cis-dodecanoate

mcl-PHA production in these strains, we presume that our bacterial strains possess a de novo fatty acid biosynthesis pathway for the synthesis of PHA [29]. Huijberts et al. (1992) reported that the presence of both saturated and unsaturated hydroxyl fatty acids in PHA may result from a possible linkage between de novo fatty acid biosynthesis and PHA biosynthesis via $\beta$-oxidation [21]. Here, we report that Acinetobacter sp. ASC1 and Bacillus sp. ASC4 isolated in this study could produce mcl-PHAs with high 3H5DD content (>99 mol \%) from crude glycerol. To our knowledge, there are a few reports regarding Enterobacter strains capable of PHA production [30-34]. Among them, E. cloacae SU-1 produced mcl-PHA consisting of $3 \mathrm{HO}$ and $3 \mathrm{HHx}$ using glucose or lactose [31], and Enterobacter strain FAK 1384 produced mcl-PHA containing $62 \mathrm{~mol} \% 3 \mathrm{HD}, 18 \mathrm{~mol} \%$ 3HO, $12 \mathrm{~mol} \% 3 \mathrm{H} 5 \mathrm{DD}, 7.6 \mathrm{~mol} \% 3 \mathrm{HDD}, 0.3 \mathrm{~mol} \%$ $3 \mathrm{HHx}$ and $1.3 \mathrm{~mol} \% 3 \mathrm{HTD}$ using copra oil [34]. The present study is the first report that an Enterobacter strain accumulated PHAs using crude glycerol. Enterobacter sp. ASC3 accumulated $17.5 \pm 0.2 \mathrm{~g} / \mathrm{L}$ mcl-PHAs (total cell dry mass $33.1 \pm 0.1 \mathrm{~g} / \mathrm{L}$ with $47.2 \pm 2.2 \mathrm{wt} \%$ PHA content) containing $\mathrm{HO}(10 \pm 2.2 \mathrm{~mol} \%)$ and $3 \mathrm{H} 5 \mathrm{DD}(90 \pm 2.7 \mathrm{~mol} \%)$. The characterization of PHA biosynthesis genes in all these bacterial strains will be carried out in the future.

\section{Molecular mass distribution}

The results of molecular mass measurements of the analyzed PHA samples, as estimated by gel permeation chromatography (GPC) experiments with polystyrene standards, are shown in Table 6 . The highest values of number-average molecular weight $\left(M_{\mathrm{N}}\right)$ and weight-average molecular weight $\left(M_{\mathrm{W}}\right)$ were obtained from Enterobacter sp. ASC3 culture. The lowest $M_{\mathrm{N}}$ and $M_{\mathrm{W}}$ values were obtained from Pseudomonas sp. ASC2. The low molecular weight of the PHAs produced may be because waste glycerol causes the termination of chain propagation through the covalent esterification of glycerol to PHA in a chain terminating position $[35,36]$.

Notably, all of the mcl-PHAs produced in this study were amorphous polymers similar to the report by Song et al. (2008), which revealed that the major components $3 \mathrm{HO}, 3 \mathrm{HD}$ and $3 \mathrm{HDD}$ from waste vegetable oil are involved in the production of mcl-PHAs [37]. One possible factor in production of polymers with amorphous properties is the lack of PHB monomers incorporated in the copolymer and the use of saturated 


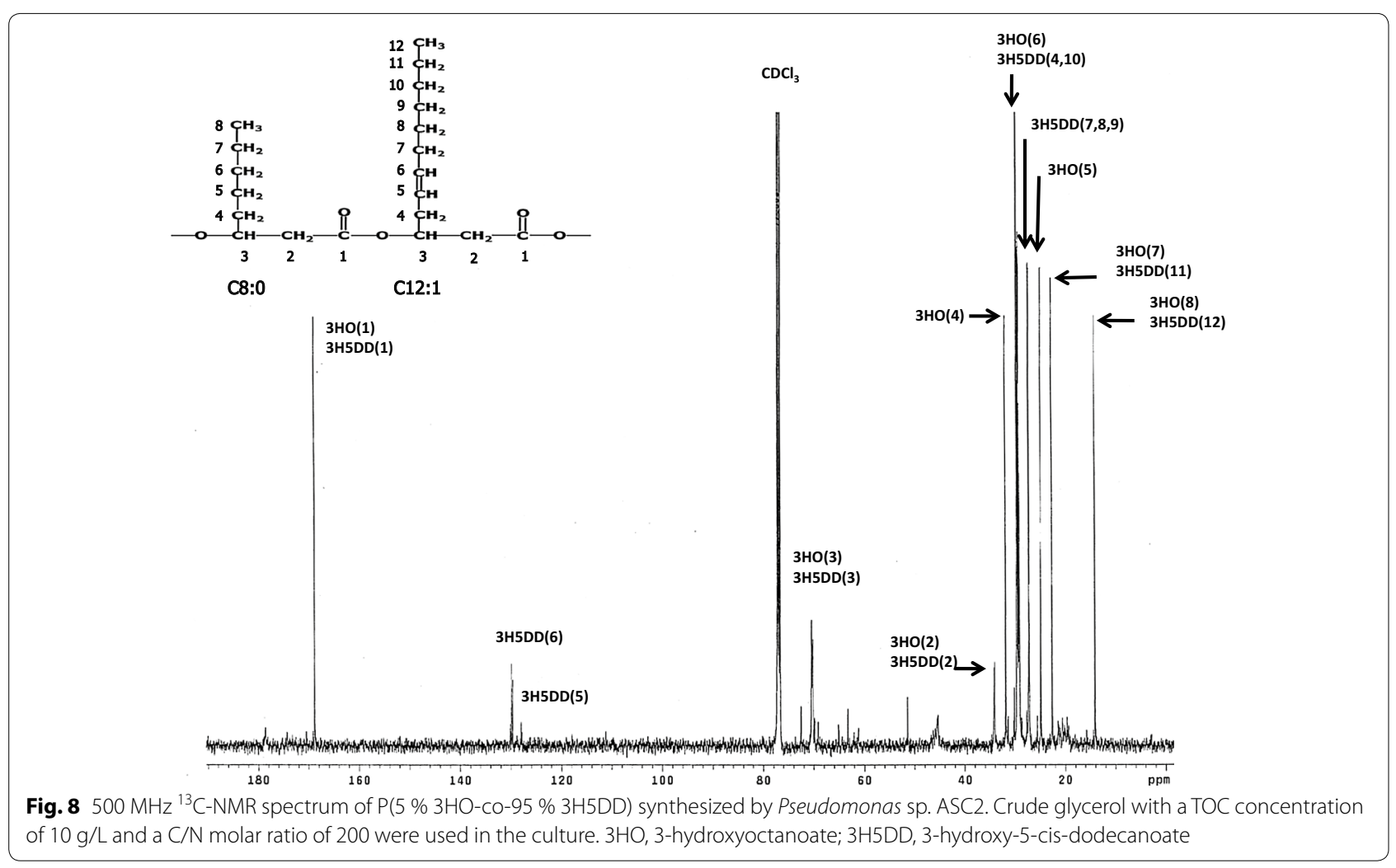

Table 5 Chemical shift data (in ppm) from ${ }^{13} \mathrm{C}$ NMR spectra of PHA samples

\begin{tabular}{llr}
\hline Carbon $^{\text {a }}$ & \multicolumn{2}{l}{$\begin{array}{l}\text { Repeating units identified in PHA } \\
\text { sample }\end{array}$} \\
\cline { 2 - 3 } & 3HO & 3H5DD \\
\hline 1 & 169.4 & 169.4 \\
2 & 34.1 & 34.1 \\
3 & 70.8 & 70.9 \\
4 & 32.1 & 30.2 \\
5 & 27.8 & 128.1 \\
6 & 31.5 & 130.1 \\
7 & 22.5 & 28.2 \\
8 & 14.0 & 28.3 \\
9 & & 28.4 \\
10 & & 30.5 \\
11 & & 22.5 \\
12 & & 14.0 \\
\hline
\end{tabular}

${ }^{a}$ The number assignments for the carbons of the repeating units $3 \mathrm{HO}$ and 3H5DD are shown in Fig. 8

$3 \mathrm{HO}$ and unsaturated 3H5DD monomers. Polymer properties are highly dependent on factors such as the aliphatic chain lengths of the individual monomers, which in turn can impact crystallinity. A high number of amorphous regions may be induced by long chains and cis-type olefinic $\left(\mathrm{C}_{12: 1}\right)$ groups in the side chains, which both perturb the packing for crystallization. Therefore, the produced mcl-PHAs were not filmable polymers but were adhesive. Preusting et al. (1990) also reported that the presence of unsaturated rather than saturated end groups somehow prevented a crystalline arrangement of the polymeric chains, resulting in an amorphous polymer [38]. Interestingly, Pappalrado et al. (2014) applied a technique to prepare a film sheet by floating a toluene solution on a water surface and successfully obtained a transparent film of mcl-PHAs consisting of six monomers: $3 \mathrm{HHx}, 3 \mathrm{HO}, 3 \mathrm{HD}, 3 \mathrm{HDD}, 3 \mathrm{H} 5 \mathrm{DD}$ and cis 3-hydroxydodec-6-enoate (3H6DD, $\mathrm{C}_{12: 1} \Delta^{6}$ ) [17]. This technique may be applicable to the mcl-PHAs we produced. Sjögren et al. (2003) reported on the chemical characterization of four anti-fungal substances, 3-hydroxydecanoic acid, 3-hydroxy-5-cis-dodecenoic acid, 3-(R)-hydroxydodecanoic acid and 3-hydroxytetradecanoic acid, from Lactobacillus plantarum MiLAB 14. The mixtures of these 3-hydroxy fatty acids showed antifungal activities against different molds and yeasts with minimum inhibitory concentrations between 10 and $100 \mu \mathrm{g} / \mathrm{mL}$ [39]. Thus, mcl-PHAs consisting of a large percentage of unsaturated 3H5DD may be applicable in the food industry. 


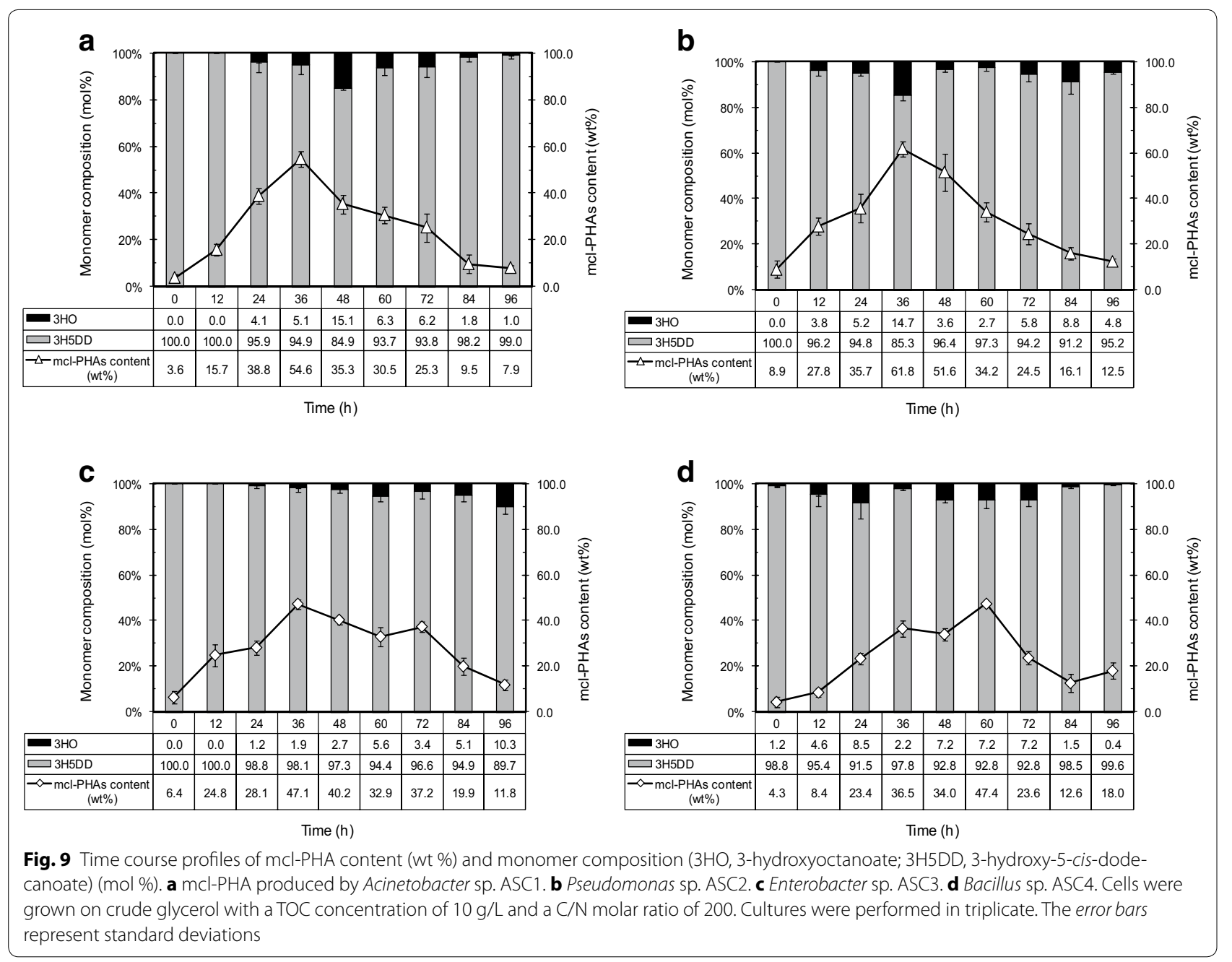

Table 6 Molecular weights of P(3HO-co-3H5DD) samples produced in batch cultivation

\begin{tabular}{|c|c|c|c|c|c|}
\hline \multirow[t]{2}{*}{ Sample } & \multicolumn{2}{|c|}{$\begin{array}{l}\text { PHA composi- } \\
\text { tion (mol \%) }\end{array}$} & \multicolumn{3}{|c|}{ Molecular weight } \\
\hline & $3 \mathrm{HO}$ & $3 \mathrm{H} 5 \mathrm{DD}$ & $M_{n}$ & $M_{w}$ & $M_{w} / M_{n}$ \\
\hline Acinetobacter sp. ASC1 & 1 & 99 & $4.7 \times 10^{4}$ & $8.8 \times 10^{4}$ & 1.9 \\
\hline Pseudomonas sp. ASC2 & 5 & 95 & $3.6 \times 10^{4}$ & $6.5 \times 10^{4}$ & 1.8 \\
\hline Enterobacter sp. ASC3 & 10 & 90 & $8.9 \times 10^{4}$ & $14.5 \times 10^{4}$ & 1.6 \\
\hline Bacillus sp. ASC4 & 0 & 100 & $6.6 \times 10^{4}$ & $14.1 \times 10^{4}$ & 2.2 \\
\hline
\end{tabular}

$M_{n}$ number average molecular weight, $M_{w}$ weight average molecular weight, $M_{w} / M_{n}$ the polydispersity index, used as a measure of the broadness of a molecular weight distribution of a polymer. The larger the polydispersity index, the broader the molecular weight. Step polymerization reactions typically yield $\mathrm{M}_{\mathrm{w}} / \mathrm{M}_{\mathrm{n}}$ values of around 2.0

\section{Conclusions}

The results presented herein permit the production of mcl-PHAs from waste glycerol by newly characterized bacterial strains screened from soil in Thailand. In this context, the interest in the production of mcl-PHAs lies in its potential use of waste glycerol which is otherwise a significant issue for waste water management. We highlight the high percentage of unsaturated monomers of 3H5DD obtained in this study, which may be useful for biomaterial applications in addition to serving in bioactive compounds to be used in the food industry.

\section{Methods \\ Microorganisms}

Bacteria were isolated from soil contaminated with used cooking oil in Thailand. The bacterial strains were maintained by monthly subculturing on nutrient agar slants. Stock cultures were maintained at $-80{ }^{\circ} \mathrm{C}$ in a $15 \%(\mathrm{v} / \mathrm{v})$ glycerol solution.

\section{Carbon sources}

Crude glycerol and refined glycerol were provided by Dr. Panu Punnarak, Witcorp Products Ltd. (a biodiesel factory at Tumbon Thasai, Amphur Muang, Samut-Sakorn, 
Thailand) during biodiesel manufacturing in 2010 and 2014. Used-cooking oil is used by this industry to produce biodiesel. The crude glycerol was used without any purification steps. The compositions of the crude glycerol and refined glycerol are shown in Table 2.

\section{Morphological and taxonomic identification}

Cellular morphology after Gram-staining was checked using light microscopy. The Hucker method [40] was used for Gram-staining. Preliminary screening for PHA production was performed by comparative staining using modified Nile blue A $[41,42]$ and Sudan Black B [43] staining methods. Cell morphology and PHA granules were also observed by TEM. For TEM, diluted culture from production medium was fixed in $2 \%(\mathrm{v} / \mathrm{v})$ glutaraldehyde containing $2 \%(\mathrm{v} / \mathrm{v})$ paraformaldehyde in $0.1 \mathrm{M}$ phosphate buffer ( $\mathrm{pH} 7.2)$ and was postfixed in $1 \%(\mathrm{w} / \mathrm{v})$ osmium tetroxide. The cells were dehydrated in an ascending series of ethanol concentrations from 35 to $100 \%$ and were embedded in Spurr resin (EMS, PA, USA). Thin sections were prepared with a LKB 2088 Ultratome V (Surrey, UK), stained with $2 \%(\mathrm{w} / \mathrm{v})$ uranyl acetate and $2 \%(\mathrm{w} / \mathrm{v})$ lead citrate and examined with a JEOL (TEM 2100) transmission electron microscope at an accelerating voltage of $80 \mathrm{kV}$. The catalase activity assay was performed by the detection of bubble formation in $3 \%(\mathrm{w} / \mathrm{v})$ hydrogen peroxide solution after incubating the cells in nutrient medium for 18-24 h. The ability to grow by utilizing substrates such as glucose, fructose, lactose, sucrose, maltose, and galactose was tested by inoculating the bacterial strains into basal medium supplemented with $2 \%(\mathrm{w} / \mathrm{v})$ of each carbohydrate, respectively; the cells were incubated at $30{ }^{\circ} \mathrm{C}$ for 3 days. Starch hydrolysis, gelatin hydrolysis, hydrogen sulfide production, nitrate reduction, the Methyl RedVoges Proskauer (MR-VP) test, and the citrate utilization test were performed. Acid production from carbohydrates was determined in basal medium that was supplemented with various carbohydrates [44]. All assays were performed three times.

\section{S rDNA gene sequencing}

Genomic DNA was prepared from colonies using the Wizard Genomic DNA Purification Kit (Promega, USA) and was used for PCR. 16S rDNA was amplified using the primers 27F (5'-AGAGTTTGATCMTGGCTCAG-3') and 1492R (5'-TACGGYTACCTTGTTACGACTT-3'). The PCR reaction and $16 \mathrm{~S}$ rDNA sequencing were performed at the Macrogen service center (Macrogen Inc., Seoul, Korea). To avoid misreading due to PCR error, sequencing of the PCR fragments was repeated at least twice. The BLASTN program (http://www.ncbi.nlm. nih.gov/BLAST/; NCBI, Bethesda, MD, USA) was used for gene homology searching with the standard default parameters.

\section{Phylogenetic analysis of 165 rDNA gene sequences}

The nucleotide sequences obtained were analyzed using DNASIS-MAC software (version 2.05; Hitachi Software Engineering Co. Ltd., Yokohama, Japan). Multiple alignments of the determined sequences were performed using the CLUSTAL X program, version 1.83 [45]. Phylogenetic trees were constructed by the neighbor-joining method [46], and phylogenetic analysis was performed using the PHYLIP version 3.572c package [47]. The percentage confidence was estimated by bootstrap analysis with 100 replications.

\section{Culture conditions}

Shaken flask experiments were performed in 250-mL Erlenmeyer flasks containing $50 \mathrm{~mL}$ of medium. The preculture medium was the same as previously described [48]. The pre cultures were grown on a rotary shaker $(200 \mathrm{rpm})$ at $30{ }^{\circ} \mathrm{C}$ for $24 \mathrm{~h}$. Cells were harvested by centrifugation, washed to remove the nitrogen source and resuspended in $100 \mathrm{~mL}$ of $0.85 \%$ sodium chloride solution. The cells were separately inoculated into production medium, a mineral salt medium [48] containing total organic carbon at varying concentrations $(5,10$ or $20 \mathrm{~g} / \mathrm{L}$ ). The cultivation was performed in 500-mL Erlenmeyer flasks containing $100 \mathrm{~mL}$ of production medium with shaking at $200 \mathrm{rpm}$ at $30{ }^{\circ} \mathrm{C}$ for $96 \mathrm{~h}$, and culture samples were taken at $12 \mathrm{~h}$ intervals. The effect of the mole ratio of $\mathrm{C} / \mathrm{N}$ on the relationship between specific growth rate, $\mu(1 / \mathrm{h})$, and specific production rate, $\rho$ (g $\mathrm{PHA} / \mathrm{g} \mathrm{CDM} / \mathrm{h}$ ), was investigated in detail for $\mathrm{C} / \mathrm{N}$ values of 4 and 200 and without a nitrogen source.

For batch experiments, $500 \mathrm{~mL}$ of seed culture were prepared in flasks and grown on a rotary shaker at $30{ }^{\circ} \mathrm{C}$ at $200 \mathrm{rpm}$ for $24 \mathrm{~h}$. The cells were harvested by centrifugation, washed to remove the nitrogen source and resuspended in $100 \mathrm{~mL}$ of $0.85 \% \mathrm{NaCl}$ solution. The cells were then inoculated into a synthetic medium containing $3.4 \mathrm{~g} / \mathrm{L} \mathrm{KH}_{2} \mathrm{PO}_{4}, 5.8 \mathrm{~g} / \mathrm{L} \mathrm{K}_{2} \mathrm{HPO}_{4}, 0.12 \mathrm{~g} / \mathrm{L} \mathrm{MgSO}_{4} \cdot 7 \mathrm{H}_{2} \mathrm{O}$, $5.0 \mathrm{~g} / \mathrm{L} \mathrm{Na} \mathrm{C}_{6} \mathrm{H}_{5} \mathrm{O}_{7}$, and $1 \mathrm{~mL}$ of trace elements solution $\left[1.67 \mathrm{~g} / \mathrm{L} \quad \mathrm{CaCl}_{2} \cdot 2 \mathrm{H}_{2} \mathrm{O}, 2.78 \mathrm{~g} / \mathrm{l} \quad \mathrm{ZnSO}_{4} \cdot 7 \mathrm{H}_{2} \mathrm{O}\right.$, $0.29 \mathrm{~g} / \mathrm{L} \mathrm{FeSO} \cdot 7 \mathrm{H}_{2} \mathrm{O}, 1.98 \mathrm{~g} / \mathrm{L} \mathrm{MnCl}_{2} \cdot 4 \mathrm{H}_{2} \mathrm{O}, 0.17 \mathrm{~g} / \mathrm{L}$ $\mathrm{CuCl}_{2} \cdot 2 \mathrm{H}_{2} \mathrm{O}$ ] in a 5 -L bioreactor (MBF-500ME, EYELA, Tokyo Rikakikai Co. Ltd., Tokyo, Japan) that was interfaced with an EPC control box (EPC-1000, EYELA, Tokyo Rikakikai Co. Ltd.). The working volume of the batch cultures was $3 \mathrm{~L}$. The fermentation temperature was $30{ }^{\circ} \mathrm{C}$, and the $\mathrm{pH}$ value was maintained at 7.0 throughout the experiments. The values for these parameters were monitored and recorded using the online program TK97 Data Record version 2.04 (EYELA, Tokyo Rikakikai Co. Ltd.). 


\section{Analytical methods}

Growth was calculated using cell dry mass. Culture broth was centrifuged at $3000 \times g$ for $10 \mathrm{~min}$. The supernatant was used to determine total organic carbon concentrations. The cell pellet was washed with acetone and centrifuged at $3000 \times g$ for $10 \mathrm{~min}$ to remove glycerol and fatty acid residue. The cells were suspended in $0.85 \% \mathrm{NaCl}$ solution and the cell suspension was filtered through pre weighed cellulose nitrate membrane filters (pore size 0.22 $\mu \mathrm{m}$, Sartorius, Goettingen, Germany) and dried at $80^{\circ} \mathrm{C}$ for 2 days. The net biomass was defined as the residual biomass, which was calculated by subtracting the amount of PHA from the total biomass. The PHAs in dried cells were methyl-esterified in a mixture of chloroform and $3 \%$ methanol-sulfuric acid (1:1 v/v), as described by Braunegg [49]. The resulting methyl esters of the monomers were quantified using GC (Model CP3800, Varian Inc., Walnut Creek, CA, USA) with a Cabowax-PEG capillary column $(0.25 \mu \mathrm{m} \mathrm{df}, 0.25 \mathrm{~mm}$ ID, $60 \mathrm{~m}$ length, Varian Inc.). The internal standard was benzoic acid, and the external standards were PHB, PHBV, n-octanoic acid and n-decanoic acid (Sigma-Aldrich Corp., St. Louis, MO, USA). The PHA compositions and the mole fractions were confirmed by ${ }^{1} \mathrm{H}$ and ${ }^{13} \mathrm{C}$ NMR (Varian Inova $600 \mathrm{MHz}$; Palo Alto, CA, USA). The $\mathrm{NH}_{4}^{+}$concentration in the culture medium was determined using a colorimetric assay [50]. To determine the quantities of total carbon (TC), inorganic carbon (IC) and organic carbon (TOC), crude glycerol was analyzed with a Total Organic Carbon Analyzer (Shimadzu TOC-Vcsh, Shimadzu Corporation, Nakagyo-ku, Kyoto, Japan) at the Petroleum and Petrochemical College of Chulalongkorn University, Bangkok, Thailand. The total carbon in the crude glycerol was $300.9 \mathrm{~g} / \mathrm{L}$.

\section{PHA extraction and purification}

Harvested cells were dried and packed in filter paper (Whatman 1002-042) and refluxed in hot chloroform in a Soxhlet to extract the PHAs from the dried cells. The PHAs were recovered from the chloroform by precipitation in $n$-hexane. The precipitation step was repeated three times [51].

\section{Chemical structure analysis}

${ }^{1} \mathrm{H}$ and ${ }^{13} \mathrm{C}$ NMR spectra of PHA samples were recorded on a Varian Inova $500 \mathrm{MHz}$ instrument. The chemical shifts are reported in parts per million (ppm) relative to chloroform as an internal reference. Spectra were recorded using $5 \%(\mathrm{w} / \mathrm{w})$ polymer solutions in $\mathrm{CDCl}_{3}$ with the following parameters: $25^{\circ} \mathrm{C}$, pulse of $90^{\circ}$, width of $8003.2 \mathrm{~Hz}, 5.0 \mathrm{~s}$ relaxation delay, and $0.2 \mathrm{~Hz}$ line broadening. Two dimensional- ${ }^{1} \mathrm{H}$-correlation spectroscopy $\left(2 \mathrm{D}-{ }^{1} \mathrm{H}-\mathrm{COSY}\right)$ was performed in combination with ${ }^{1}$ NMR on a Bruker AM 400 MHz FT-NMR (BrukerBioSpin Corporation, Woodland, TX, USA).

Measurement of the molecular weight distribution of PHAs The molecular weight of PHAs was determined by a GPC system with a refractive index detector (Class-VP series with software version V6.14; Shimadzu Corp., Tokyo, Japan) using a Styragel HT6E column (Waters, Milford, MA, USA). Chloroform was used as the elution solvent at a flow rate of $1.0 \mathrm{~mL} / \mathrm{min}$. The operating temperature was maintained at $40{ }^{\circ} \mathrm{C}$. The calibration curve was determined using low polydispersity polystyrene standards $\left(M_{\mathrm{W}}=4.56 \times 10^{2}\right.$, $2.98 \times 10^{3}, 3.79 \times 10^{4}, 9.64 \times 10^{4}, 1.90 \times 10^{5}$, and $7.06 \times 10^{5}$; Tosoh Corp., Tokyo, Japan). The GPC data were calculated using an integrator for the number average molecular weight $\left(M_{\mathrm{N}}\right)$, the weight average molecular weight $\left(M_{\mathrm{W}}\right)$, and the polydispersity index $\left(M_{\mathrm{W}} / M_{\mathrm{N}}\right)$.

\section{Abbreviations}

$\mathrm{C} / \mathrm{N}$ : molar ratio of carbon to nitrogen; PHA: polyhydroxyalkanoate; CDM: cell dry mass;RCM: residual-cell mass; 3HB: 3-hydroxybutyrate $\left(\mathrm{C}_{4}\right)$; 3HHx: 3-hydroxyhexanoate $\left(\mathrm{C}_{6}\right)$; $3 \mathrm{HO}$ : 3-hydroxyoctanoate $\left(\mathrm{C}_{8}\right)$; 3HD: 3-hydroxydecanoate $\left(\mathrm{C}_{10}\right)$; 3HDD: 3-hydroxydodecanoate $\left(\mathrm{C}_{12: 0}\right)$; 3H5DD: 3-hydroxy-5-cis-dodecanoate $\left(\mathrm{C}_{12: 1} \Delta^{5}\right)$; 3H6DD: 3-hydroxy-6-cis-dodecanoate $\left(\mathrm{C}_{12: 1} \Delta^{6}\right)$; 3HTD: 3-hydroxytetradecanoate $\left(\mathrm{C}_{14}\right)$.

\section{Greek letters}

$M$ : specific growth rate $(1 / \mathrm{h}) ; P$ : specific production rate of polymer (g PHA/g CDM/h).

\section{Authors' contributions}

AM performed the experiments. TB and JP co-performed the experiments, particularly on taxonomical identification. SCN designed all the experiments, supervised the research and wrote and edited the manuscript. All authors read and approved the final manuscript.

\section{Author details}

${ }^{1}$ Department of Microbiology, Faculty of Science, Chulalongkorn University, Phayathai Road, Patumwan, Bangkok 10330, Thailand. ${ }^{2}$ Program in Biotechnology, Faculty of Science, Chulalongkorn University, Phayathai Road, Patumwan, Bangkok 10330, Thailand.

\section{Acknowledgements}

This research was partially supported by the Ratchadapiseksomphot Endowment Fund under the Outstanding Research Performance Program, Chulalongkorn University, to Suchada Chanprateep Napathorn. This research was also supported in part by the Thailand Research Fund for Master Research Grants TRF-MAG Window I to Suchada Chanprateep Napathorn and Amtiga Muangwong. The authors thank Dr. Panu Punnarak at Witcorp Products Ltd. (Thailand) for providing the crude waste glycerol obtained from the biodiesel manufacturing industry.

\section{Competing interests}

The authors declare that they have no competing interests.

Received: 26 January 2016 Accepted: 9 March 2016 Published online: 17 March 2016 


\section{References}

1. Chanprateep S. Current trends in biodegradable polyhydroxyalkanoates. J Biosci Bioeng. 2010;110:621-32.

2. United Nations. Report of the World Commission on Environment and Development, General Assembly Resolution 42/187. 1987. (http://www. un-documents.net/a42r187.htm), Accessed 11 Jan 2016.

3. Akiyama M, Tsuge T, Doi Y. Environmental life cycle comparison of polyhydroxyalkanoates produced from renewable carbon resources by bacterial fermentation. Polym Degrad Stab. 2003;80:183-94.

4. Kim S, Dale BE. Lifecycle assessment study of biopolymer (polyhydroxyalkanoates) derived from no-tilled corn. Int J Life Cycle Assess. 2005;10:200-10.

5. Harding KG, Dennis JS, von Blottnitz H, Harrison STL. Environmental analysis of plastic production processes: comparing petroleum based polypropylene and polyethylene with biologically-based poly- $\beta$-hydroxybutyric acid using life cycle analysis. J Biotechnol. 2007;130:57-66.

6. Ma F, Hanna MA. Biodiesel production: a review. Bioresour Technol. 1999;70:1-15

7. García IL, López JA, Dorado MP, Kopsahelis N, Alexandri M, Papanikolaou $\mathrm{S}$, et al. Evaluation of by-products from the biodiesel industry as fermentation feedstock for poly(3-hydroxybutyrate-co-3-hydroxyvalerate) production by Cupriavidus necator. Bioresour Technol. 2013;130:16-22.

8. Jaturapaktrarak C, Napathorn SC, Cheng M, Okano K, Ohtake H, Konda $\mathrm{H}$. In vitro conversion of glycerol to lactate with thermophilic enzymes. Bioresour Bioprocessing. 2014;1:18.

9. Yang F, Hanna MA, Sun R. Value-added uses for crude glycerol-a byproduct of biodiesel production. Biotechnol Biofuels. 2012;5:13.

10. Abidin SZ, Patel D, Saha B. Quantitative analysis of fatty acids composition in the used cooking oil (UCO) by gas chromatography-mass spectrometry (GC-MS). Can J Chem Eng. 2013;91:1896-903.

11. Hansen CF, Hernandez A, Mullan BP, Moore K, Trezona-Murray M, King RH, et al. A chemical analysis of samples of crude glycerol from the production of biodiesel in Australia, and the effects of feeding crude glycerol to growing-finishing pigs on performance, plasma metabolites and meat quality at slaughter. Anim Prod Sci. 2009;49:154-61.

12. Hu S, Luo X, Wan C, Li Y. Characterization of crude glycerol from biodiesel plants. J Agric Food Chem. 2012;60:5915-21.

13. Ashby RD, Solaiman DKY, Foglia TA. Bacterial poly(hydroxyalkanoate) polymer production from the biodiesel co-product stream. J Polym Environ. 2004;12:105-12

14. Ibrahim MHA, Steinbüchel A. Zobellella denitrificans strain MW1, a newly isolated bacterium suitable for poly(3-hydroxybutyrate) production from glycerol. J Appl Microbiol. 2010;108:214-25.

15. Cavalheiro JMBT, de Almeida MCMD, Grandfils C, da Fonseca MMR. Poly(3-hydroxybutyrate) production by Cupriavidus necator using waste glycerol. Process Biochem. 2009;44:509-15.

16. Kawata Y, Aiba S. Poly(3-hydroxybutyrate) production by isolated Halomonas sp. KM-1 using waste glycerol. Biosci Biotechnol Biochem. 2010;74:175-7.

17. Pappalrado F, Fragala M, Mineo PG, Damigella A, Catara AF, Palmeri $\mathrm{R}$, et al. Production of filmable medium-chain-length polyhydroxyalkanoates produced from glycerol by Pseudomonas mediterranea. Int J Biol Macromol. 2014;65:89-96.

18. Sanjid A, Masjuki HH, Kalam MA, Rhaman SMA, Abedin MJ, Palash SM. Impact of palm, mustard, waste cooking oil and Calophyllum inophyllum biofuels on performance and emission of Cl engine. Renew Sust Energ Rev. 2013;27:664-82.

19. Ghazali WNMW, Mamat R, Hasjuki HH, Najafi G. Effects of biodiesel from different feed stocks on engine performance and emissions: a review. Renew Sust Energ Rev. 2015;51:585-602.

20. Haywood GW, Anderson AJ, Ewing DF, Dawes EA. Accumulation of a polyhydroxyalkanoate containing primarily 3-hydroxydecanoate from simple carbohydrate substrates by Pseudomonas sp. strain NCIMB 40135. Appl Environ Microbiol. 1990;56:3354-9.

21. Huijberts GNM, Eggink G, Waard P, Huisman GW, Witholt B. Pseudomonas putida KT2442 cultivated on glucose accumulates poly(3-hydroxyalkanoates) consisting of saturated and unsaturated monomers. Appl Environ Microbiol. 1992;58:536-44.

22. Matsusaki H, Abe H, Doi Y. Biosynthesis and properties of poly(3hydroxybutyrate-co-3-hydroxyalkanoates) by recombinant strains of Pseudomonas sp. 61-3. Biomacromolecules. 2000;1:17-22.
23. Fukui T, Kato M, Matsusaki H, Iwata T, Doi Y. Morphological and ${ }^{13} \mathrm{C}$-nuclear magnetic resonance studies for polyhydroxyalkanoate biosynthesis in Pseudomonas sp. 61-3. FEMS Microbiol Lett. 1998;164:219-25.

24. Timm A, Steinbüchel A. Formation of polyesters consisting of mediumchain-length 3-hydroxyalkanoic acids from gluconate by Pseudomonas aeruginosa and other fluorescent pseudomonads. Appl Environ Microbiol. 1990;56:3360-7.

25. Agnew DE, Stevermer AK, Youngquist JT, Pfleger BF. Engineering Escherichia coli for production of $\mathrm{C}_{12}-\mathrm{C}_{14}$ polyhydroxyalkanoate from glucose. Metab Eng. 2012;14:705-13.

26. Liu Q, Luo G, Zhou XR, Chen GQ. Biosynthesis of poly(3-hydroxydecanoate) and 3-hydroxydodecanoate dominating polyhydroxyalkanoates by $\beta$-oxidation pathway inhibited Pseudomonas putida. Metab Eng. 2011;13:11-7.

27. Poblete-Castro I, Escapa IF, Jäger C, Puchalka J, Lam CMC, Schomburg D, Prieto MA. Martins dos Santos VAP. The metabolic response of P. putida KT2442 producing high levels of polyhydroxyalkanoate under single-and multiple-nutrient-limited growth: highlights from a multi-level omics approach. Microb Cell Fact. 2012;11:34.

28. Shahid S, Mosrati R, Ledauphin J, Amiel C, Fontaine P, Gaillard JL, Corroler D. Impact of carbon source and variable nitrogen conditions on bacterial biosynthesis of polyhydroxyalkanoates: evidence of an atypical metabolism in Bacillus megaterium DSM 509. J Biosci Bioeng. 2013;116:302-8.

29. Song JH, Jeon CO, Choi MH, Yoon SC, Park W. Polyhydroxyalkanoate (PHA) production using waste vegetable oil by Pseudomonas sp. strain DR2. J Microbiol Biotechnol. 2008;18:1408-15.

30. Chen $Z$, Li Y, Wen Q. Isolation of a PHA producing strain with butyric acid as the carbon source and its shaking-flask fermentation character. Huan Jing Ke Xue. 2010;31:828-32.

31. Samrot AV, Avinesh RB, Sukeetha SD, Senthilkumar P. Accumulation of poly[(R)-3-hydroxyalkanoates] in Enterobacter cloacae SU-1 during growth with two different carbon sources in batch culture. Appl Biochem Biotechnol. 2011;163:195-203.

32. Arumugam A, Sandhya M. Ponnusami Biohydrogen and polyhydroxyalkanoate co-production by Enterobacter aerogenes and Rhodobacter sphaeroides from Calophyllum inophyllum oil cake. Bioresour Technol. 2014;164:170-6.

33. Naheed N, Jamil N. Optimization of biodegradable plastic production on sugar cane molasses in Enterobacter sp. SEL2. Braz. J Microbiol. 2014;45:417-26.

34. Wecker P, Moppert X, Simon-Colin C, Costa B, Berteaux-Lecellier V. Discovery of a mcl-PHA with unexpected biotechnical properties: the marine environment of French Polynesia as a source for PHA-producing bacteria. AMB Exper. 2015;5:74.

35. Ashby RD, Solaiman DKY, Foglia TA. Synthesis of short-/medium-chainlength poly(hydroxyalkanoate) blends by mixed culture fermentation of glycerol. Biomacromolecules. 2005;6:2106-12.

36. Koller M, Bona R, Braünegg $G$, Hermann $C$, Horvat $P$, Kroutil M, et al. Production of polyhydroxyalkanoates from agricultural waste and surplus materials. Biomacromolecules. 2005;6:561-5.

37. Song JH, Jeon CO, Choi MH, Yoon SC, Park W. Polyhydroxyalkanoate (PHA) production using waste vegetable oil by Pseudomonas sp. strain DR2. J Microbiol Biotechnol. 2008;18:1408-15.

38. Preusting H, Nijenhuis A, Witholt B. Physical characteristics of poly(3hydroxyalkanoates) and poly(3-hydroxyalkenoates) produced by Pseudomonas oleouorans grown on aliphatic hydrocarbons. Macromolecules. 1990;23:4220-4.

39. Sjögren J, Magnusson J, Broberg A, Schurer J, Kenne L. Antifungal 3-hydroxy fatty acids from Lactobacillus plantarum MiLAB 14. Appl Environ Microbiol. 2003;69:7554-7.

40. Murray RGE, Doetsch RN, Robinow CF. Determinative and cytological light microscopy. In: Gerhardt P, Murray RGE, Wood WA, Krieg NR, editors. Methods for general and molecular bacteriology. Washington: American Society for Microbiology; 1994. p. 22-41.

41. Ostle AG, Holt JG. Nile blue A as a fluorescent stain for poly-beta-hydroxybutyrate. Appl Environ Microbiol. 1982;44:238-41.

42. Spiekermann P, Rehm BH, Kalscheuer R, Baumeister D, Steinbüchel A. A sensitive viable-colony staining method using Nile red for direct screening of bacteria that accumulate polyhydroxyalkanoic acids and other lipid storage compounds. Arch Microbiol. 1999;171:73-80. 
43. López-Cortés A, Lanz LA, Garcia MJQ. Screening and isolation of PHBproducing bacteria in a polluted marine microbial mat. Microb Ecol. 2008;56:112-20.

44. Smibert RM, Krieg NR. Phenotypic characterization. In: Gerhardt P, Murray RGE, Wood WA, Krieg NR, editors. Methods for general and molecular bacteriology. Washington: American Society for Microbiology; 1994. p. 607-54.

45. Thompson JD, Higgins DG, Gibson TJ, Clustal W. Improving the sensitivity of progressive multiple sequence weighing, position-specific gap penalties and weight matrix choice. Nucleic Acids Res. 1994;76:4350-4.

46. Kimura M. A simple method for estimating evolutionary rates of base substitution through comparative studies of nucleotide sequences. J Mol Evol. 1980;16:111-20.

47. Felsenstein J. Confidence limits on phylogenies: an approach using the bootstrap. Evolution. 1985;39:783-91.

48. Chanprateep S, Katakura Y, Shimizu H, Visetkoop S, Kulpreecha S, Shioya S. Characterization of new isolated Ralstonia eutropha strain A-04 and kinetic study of biodegradable copolyester poly(3-hydroxybutyrateco-4-hydroxybutyrate) production. J Ind Microbiol Biotechnol. 2008;35:1205-15.
49. Braünegg $G$, Sonnleitner $G$, Lafferty RM. A rapid gas chromatographic method for the determination of poly-3-hydroxubutyric acid in microbial biomass. Eur J Appl Microbiol Biotechnol. 1978;6:29-37.

50. Kemper AJ. Determination of sub-micro quantities of ammonium and nitrate in soils with phenol, sodium nitropusside and hypochloride. Geoderma. 1974;12:201-6.

51. Chanprateep S, Buasri K, Muangwong A, Utiswannakul P. Biosynthesis and biocompatibility of biodegradable poly(3-hydroxybutyrate-co-4-hydroxybutyrate). Polym Degrad Stab. 2010;95:2003-12.

\section{Submit your next manuscript to BioMed Central and we will help you at every step:}

- We accept pre-submission inquiries

- Our selector tool helps you to find the most relevant journal

- We provide round the clock customer support

- Convenient online submission

- Thorough peer review

- Inclusion in PubMed and all major indexing services

- Maximum visibility for your research

Submit your manuscript at www.biomedcentral.com/submit

() Biomed Central 